\title{
Flame index and its statistical properties measured to understand partially-premixed turbulent combustion
}

\author{
David A. Rosenberg*, Patton M. Allison, James F. Driscoll \\ Department of Aerospace Engineering, University of Michigan, Ann Arbor, MI 48109-2140, USA
}

\begin{abstract}
This work addresses some fundamental questions in the area of partially-premixed combustion-what parameters control the fraction of flamelets that are premixed (versus non-premixed), and what are the locations of high probability of premixed (versus non-premixed) combustion? To answer these questions there is a need to measure the flame index $(\xi)$ and its statistical properties, and this information previously has not been available. Flame index is +1 where a premixed flamelet exists and is -1 at the location of a non-premixed flamelet. A new method to measure flame index was developed that adds $\mathrm{NO}_{2}$ to the air; acetone is used as one component of the fuel. Laser induced fluorescence images indicate the locations of flamelets and whether the gradients of the fuel and $\mathrm{O}_{2}$ are in the same direction or not. Flame index was measured in a gas turbine model combustor that was designed at DLR that is a good example of partially-premixed combustion.

Measurements show how the mean flame index varies in space; near the fuel injector the combustion is $50 \%$ non-premixed and $50 \%$ premixed while downstream the flamelets are mostly premixed. This trend is consistent with two numerical simulations of swirl flames; however for simple lifted jet flames the premixed flamelets do not extend so far downstream. It was found that one parameter that controls the fraction of flamelets that are premixed is the ratio of the fuel injection velocity to the air velocity. Increasing this ratio increases the fraction of flamelets that are premixed because it increases the distance that the fuel stream penetrates into the more intense mixing region. Good signal-to-noise ratios of 24 (for acetone) and 13 (for $\mathrm{NO}_{2}$ ) were achieved and an uncertainty analysis is presented that is based on calibration experiments.
\end{abstract}

Keywords:

Flame index, Partially-premixed flames, PLIF, Turbulent flames

\section{Introduction}

Recently there has been a considerable amount of interest in the area of partially-premixed turbulent combustion. The term partiallypremixed indicated that premixed flames occur at some times at a point while non-premixed flames exist at other times at that same point. Partially-premixed combustion should not be confused with "stratified premixed combustion"; the latter occurs when the fuel-air mixture ratio is not uniform in space but it always remains within the flammability limits so that none of the flamelets are non-premixed. One example of partial-premixing is the base region of a lifted (initially non-premixed) jet flame [1-6]. Mixing occurs in the liftoff region and mixing may by assisted by adding co-flow air, cross-flow air, or swirling air [7-9]. A large number of practical devices burn fuel in the partially-premixed mode since the reaction zone usually is lifted from the fuel injectors that are used in automotive, gas turbine, and rocket engines.

Important questions about partially-premixed combustion are: what fraction of the flamelets are premixed, what controls this fraction,

\footnotetext{
${ }^{*}$ Corresponding author. Present Address: U.S. Naval Research Laboratory, Chemistry Division, Combustion Dynamics and Modeling Section, Code 6185 , 4555 Overlook Ave. SW, Washington, DC 20375, USA.

Email address: DavidAriRosenberg@gmail.com (David A. Rosenberg)
} 
and what are the locations where there is a high probability of premixed flamelets? For example, near the base of a lifted jet flame the Direct Numerical Simulation (DNS) of Mizobuchi et al. [2] identified many regions of premixed combustion while at downstream locations the combustion was mostly non-premixed. They argued that premixed combustion is caused by the fuel-air mixing that occurs in the shear layers within the liftoff region. Cai et al. [10] explain that another example of partially-premixed combustion is the upstream region of Sandia jet flame D [10] that is surrounded by a premixed pilot flame. A typical gas turbine combustor normally contains a relatively short, compact, and lifted flame that is expected to have regions that are partially-premixed.

To understand and to model partially-premixed combustion, a useful parameter is the Takeno flame index $(\xi)$. It was defined by Yamashita et al. [1] to be the normalized dot product of the gradients of the fuel and oxidizer mass fractions $\left(Y_{\mathrm{F}}, Y_{\mathrm{O}}\right)$ :

$$
\xi=\frac{\nabla Y_{\mathrm{F}, \text { max }} \cdot \nabla Y_{\mathrm{O}, \text { max }}}{\left|\nabla Y_{\mathrm{F}, \text { max }} \cdot \nabla Y_{\mathrm{O}, \max }\right|} .
$$

Consider the direction that is normal to a thin, wrinkled flamelet. The gradient in the fuel mass fraction is approximately a Gaussianshaped function and its maximum value $\left(\nabla Y_{\mathrm{F}, \max }\right)$ occurs approximately in the middle of the layer. The denominator in Eq. (1) is the absolute value of the scalar dot product. For the premixed case the fuel and oxidizer gradients are aligned so the flame index is +1 . For the non-premixed case the flame index is -1 if there is fuel on one side and air on the other side of the flamelet. If no flamelet exists at a location then the flame index at that location is defined to zero. As an example, suppose that there is a measurement error that causes the numerator of Eq. (1) to be $20 \%$ larger than the actual instantaneous value. This should not change the value of the flame index because the denominator always is the magnitude of the numerator. Thus the flame index only can take on values of +1 or -1 if a flamelet is present. An error in the instantaneous value of flame index occurs if the measurement error is so large that it causes the measured sign of $\xi$ to be opposite to the actual sign. This occurs infrequently, as discussed the uncertainty analysis presented below.

The global fraction of flamelets that are premixed $(\beta)$ is defined to be:

$$
\beta=\left\langle\frac{C}{A+C}\right\rangle,
$$

where $A$ and $C$ are components of the probability density function (PDF) $\operatorname{Pr}(\xi)$ of the flame index, and the brackets imply that spatial averaging is done over the entire flame. $\operatorname{Pr}(\xi)$ consists of three delta functions located at $\xi=+1,-1$, and 0 , so:

$$
\operatorname{Pr}(\xi)=A \delta(\xi+1)+B \delta(\xi)+C \delta(\xi-1),
$$

where $\delta$ is the Dirac delta function. $A$ is the probability of the occurrence of non-premixed flamelets since if $\xi=-1$ the first term in Eq. (3) becomes $A \delta(0)$, and the integral of $A \delta(0) \mathrm{d} \xi$ is $A . B$ is the probability of no flamelet, and $C$ is the probability of premixed flamelets. The mean flame index, $\bar{\xi}$, is the integral of $\xi \operatorname{Pr}(\xi) \mathrm{d} \xi$ over all values of $\xi$, which is $(C-A)$. The sum $(A+C)$ is the probability that flamelets occur, so the probability that a flamelet is premixed is $C /(A+C)$.

Previous studies that have reported values of flame index have been limited to direct numerical simulations (DNS) and large eddy simulations (LES). DNS of Mizobuchi et al. [2] and Domingo et al. [5] showed that the base of a lifted jet flame contains many cuspshaped regions and each region has a value of $\xi$ that is either +1 or -1 . A similar DNS result was reported for a lifted jet flame in a cross-flow by Grout et al. [8]. Luo et al. [9] described DNS computations of $\xi$ when swirl was added to the flow. These DNS results indicate that the lifted base region has both premixed and non-premixed structures, as does a "triple-flame" [11, 12].

To simulate partially-premixed combustion at higher Reynolds numbers than can be achieved with DNS it becomes necessary to use Large Eddy Simulation (LES). With some LES submodels the probability density function of flame index $\operatorname{Pr}(\xi)$ is determined first. Then different submodels are applied for premixed and non-premixed combustion, as described by Bray et al. [13], Domingo et al. [14], Knudsen and Pitsch [15, 16], and Patel and Menon [17]. For example, the mean volumetric reaction rate of hydrogen $\left(\mathrm{H}_{2}\right)$ in a computational cell can be set equal to:

$$
\overline{\omega_{\mathrm{H}_{2}}}=\int_{-\infty}^{+\infty} \omega_{\mathrm{H}_{2}} \operatorname{Pr}(\xi) \mathrm{d} \xi=A \omega_{\mathrm{H}_{2}, \text { nonpre }}+C \omega_{\mathrm{H}_{2}, \text { pre }}
$$


where $A$ and $C$ are components of the PDF of flame index that is defined in Eq. (3). A premixed combustion submodel simulates the premixed reaction rate $\omega_{\mathrm{H}_{2} \text {,pre }}$ while a non-premixed combustion submodel simulates $\omega_{\mathrm{H}_{2} \text {,nonpre }}$. The proposed subgrid models [13-16] for the probabilities $A$ and $C$ are similar to subgrid models of scalar dissipation rate. The resolved-scale scalar gradient is first computed from values determined on the grid points and the model assumes that the sub-grid scalar gradient is proportional to this resolved-scale gradient. For example, Domingo et al. [14] assumes that the mean flame index in a cell of size $\Delta$ is:

$$
\bar{\xi}=\mathcal{F}_{\mathrm{Z}} \chi_{\mathrm{Z}}+\mathcal{F}_{\mathrm{c}} \chi_{\mathrm{c}}
$$

The subgrid scalar dissipation rate, $\chi_{Z}$, is modeled in the standard manner to be $\Delta^{2}|\widehat{\nabla Z}|^{2} / \tau$, where $\Delta$ is the cell size, $|\widehat{\nabla Z}|$ is the magnitude of the resolved-scale mixture fraction gradient, and $\tau$ is a time constant. Reference [14] provides relations for the weighting functions $\mathcal{F}_{Z}$ and $\mathcal{F}_{\mathrm{c}}$, the reactedness dissipation rate $\chi_{\mathrm{c}}$, and the time constant $\tau$. Knudsen and Pitsch [16] propose a similar model; they also relate flame index to the gradients in mixture fraction and reactedness but in a different way than Domingo et al [14]. A different LES approach is the progress variable $(P V)$ method of Pierce and Moin [18], Ihme and See [19], and Ihme and Pitsch [20]. A flamelet library is generated by solving the flamelet equation for two independent variables (mixture fraction and progress variable). A number of other related simulations also have been reported [21-25]. There have been no assessments of the various sub-models due to the lack of measurements of the flame index.

While no measurements of flame index previously have been reported, numerous experimental studies have added acetone $\left(\mathrm{CH}_{3} \mathrm{COCH}_{3}\right)$ to track the fuel concentration alone. Recently Stöhr et al. [26] added acetone to track the fuel mole fraction within a swirl flame in the DLR Gas Turbine Model Combustor (GTMC) while they simultaneously tracked the flame boundary by recording the $\mathrm{OH}$ planar laser-induced fluorescence (PLIF) signal. However they had no way to track the oxygen $\left(\mathrm{O}_{2}\right)$ so they could not measure the flame index or the local fuel-air ratio. They did show that the acetone marker was a good indicator that fuel mole fraction just ahead of the flame surface varied by large amounts. They could not determine whether or not the mixture lies within the flammability limits. Their scatter plots indicated that instantaneous temperatures were not bimodal as would be expected in premixed combustion. Nor were their scatter plots expected for a pure non-premixed flame. They concluded that "results demonstrate a fast mixing of fuel and air but flames cannot be regarded as uniformly premixed but should be classified as partially premixed." In a related study Meier et al. [27] showed that flamelets exist because they observed thin layers in their CH PLIF images, but they could not determine which layers were premixed.

\section{Objectives}

There have been no previous measurements of flame index, $\xi$, because appropriate diagnostics were not developed prior to the present project. Raman scattering has not proved to be a viable way to measure the directions of the gradients of the fuel and $\mathrm{O}_{2}$ mass fractions that appear in Eq. (1). Two-dimensional images are required and there have been no reported simultaneous 2-D Raman images of fuel and $\mathrm{O}_{2}$ that have sufficient spatial resolution to resolve flamelets within intense turbulence. The only viable approach is to record the planar laser-induced fluorescence (PLIF) from appropriate tracer gases.

Therefore the first objective was to select two tracer gases and run CHEMKIN in order to compute the signs of the maximum gradients of the fuel mass fraction, the $\mathrm{O}_{2}$ mass fraction, and the tracer gas signals. Section 3 describes the three types of flames that were selected for the computations: laminar premixed, laminar non-premixed, and laminar partially-premixed. The second objective was to operate laminar flame calibration experiments that are described in Section 4.3. Flame index was measured and it was known a priori to be +1 at every location where a flame exists in the laminar premixed calibration flame; it is -1 at every point along the non-premixed calibration flame. Therefore any deviations from the known values represent an uncertainty. An uncertainty analysis then was performed using the calibration flame data and the results are presented in Section 4.3. Finally, Section 5 reports measurements of 
flame index in the Gas Turbine Model Combustor designed by Meier and colleagues at DLR. They previously reported many properties of this configuration but did not measure flame index.

\section{Selection of tracer gases based on CHEMKIN computations}

Tracer gases that initially were considered but were rejected include nitric oxide (NO), formaldehyde $\left(\mathrm{CH}_{2} \mathrm{O}\right)$, and carbon monoxide (CO). CHEMKIN results show that the gradients of the concentration profiles of these species undergo changes in direction within the reaction zones because these species are both formed and consumed. Thus the directions of their gradients differ from those of $\mathrm{O}_{2}$ and the fuel, respectively, so these tracer gases were not considered.

It was decided to use a fuel that consists of $79 \%$ propane $\left(\mathrm{C}_{3} \mathrm{H}_{8}\right)$ and $21 \%$ acetone $\left(\mathrm{CH}_{3} \mathrm{COCH}_{3}\right)$ by volume. The oxidizer was selected to be air with $5000 \mathrm{ppm}$ nitrogen dioxide $\left(\mathrm{NO}_{2}\right)$ added. The fuel mixture was selected because propane has nearly the same molecular diffusivity as acetone. The large mole fraction of acetone was selected to maximize the fluorescence signal. It is not argued that this is a propane-air flame with small amounts of seeding; it is a propane-acetone-air- $\mathrm{NO}_{2}$ flame. Both acetone and $\mathrm{NO}_{2}$ have excellent fluorescence yields when excited with $266 \mathrm{~nm}$ and $532 \mathrm{~nm}$ light sheets, respectively [28-42]. Acetone has been used to track the fuel concentration in flames by Thurber and Hanson [28], Shultz and Sick [31], Chong and Hochgreb [32], and Bryant et al. [33, 34]. In these studies it was recognized that there may be a small $(0.5 \mathrm{~mm}$ to $1 \mathrm{~mm})$ distance between where the acetone fluorescence disappears and where the fuel disappears, but this spatial uncertainty was argued to have no effect on the conclusions. Cattolica and others [37$40,43,44]$ have used $\mathrm{NO}_{2}$ fluorescence in reacting and non-reacting flows to track cold-flow mixing and to mark the reaction interface between unburned reactants and combustion products. However, $\mathrm{NO}_{2}$ has never been used to mark $\mathrm{O}_{2}$ gradients. It can be argued that a small $0.5 \mathrm{~mm}$ to $1 \mathrm{~mm}$ difference in the locations where the $\mathrm{O}_{2}$ and the $\mathrm{NO}_{2}$ disappear will have no effect on the effectiveness of $\mathrm{NO}_{2}$ as an indicator of $\mathrm{O}_{2}$ gradients.

Figure 1 shows profiles computed by CHEMKIN of the fluorescent signals of the two tracer gases. Table 1 shows the gradients of the propane and $\mathrm{O}_{2}$ mass fractions, as well as the gradients of the acetone and $\mathrm{NO}_{2}$ LIF signals from the CHEMKIN profiles. The GRI-Mech chemistry in CHEMKIN was augmented with the acetone mechanism of Chong and Hochgreb [32]. For the computations, the mole fractions of acetone $(0.21)$ and $\mathrm{NO}_{2}(5000 \mathrm{ppm})$ were identical to the values used in the experiment.

The CHEMKIN computations were performed for strain rates varying from $160 \mathrm{~s}^{-1}$ to $550 \mathrm{~s}^{-1}$ for both premixed and non-premixed cases. This range of strain rates corresponds to that expected in the GTMC experiment that is described in the next section. That is, r.m.s. velocity fluctuations up to $2 \mathrm{~m} / \mathrm{s}$ are expected for our flow rates, based on data of Stöhr et al. [26], so these two strain rates correspond to eddy sizes of $4 \mathrm{~mm}$ and $12 \mathrm{~mm}$, which are reasonable values for the experiment.

The acetone and $\mathrm{NO}_{2}$ signal profiles were computed using the CHEMKIN values of mole fractions along with published relations for the Boltzmann fraction and the collisional quenching terms. For acetone the calibration relation that was used was the one reported by Thurber and Hanson [28]:

$$
\frac{S_{\text {acetone }}}{S_{\text {acetone,ref }}}=\left(\frac{X_{\text {acetone }}}{X_{\text {acetone,ref }}}\right)\left(\frac{p}{p_{\text {ref }}}\right)\left[\left(\frac{T}{T_{\text {ref }}}\right)^{-1}\left(\frac{\sigma}{\sigma_{\text {ref }}}\right)\left(\frac{\phi}{\phi_{\text {ref }}}\right)\right] .
$$

The fluorescence quantum yield factor, $\phi$, includes the collisional quenching term. The absorption cross section of acetone, $\sigma$ includes the Boltzmann fraction term. Thurber and Hanson report extensive measurements of the quantity that is enclosed in square brackets in Eq. (6).

The $\mathrm{NO}_{2}$ signal in Fig. 1 was computed using the standard fluorescence equation described by Hanson et al. [36]; it is identical to Eq. (6) but it is written using the following notation:

$$
\frac{S_{\mathrm{NO}_{2}}}{S_{\mathrm{NO}_{2}, \text { ref }}}=\left(\frac{X_{\mathrm{NO}_{2}}}{X_{\mathrm{NO}_{2}, \text { ref }}}\right)\left(\frac{p}{p_{\text {ref }}}\right)\left[\left(\frac{T}{T_{\text {ref }}}\right)^{-1}\left(\frac{f}{f_{\text {ref }}}\right)\left(\frac{\left(A_{j k}+Q\right)}{\left(A_{j k}+Q\right)_{\text {ref }}}\right)^{-1}\right] .
$$




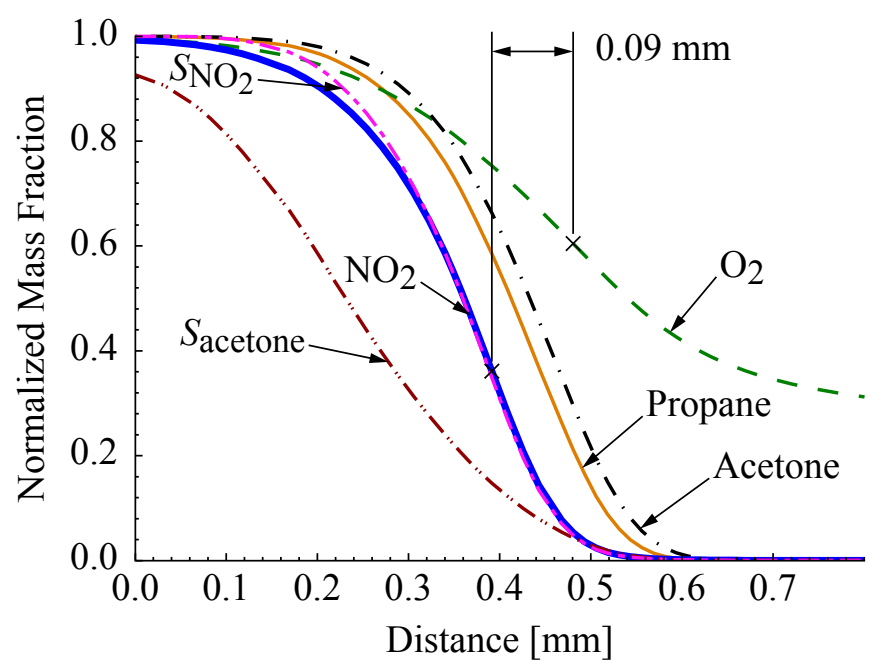

(a) Premixed CHEMKIN computation.

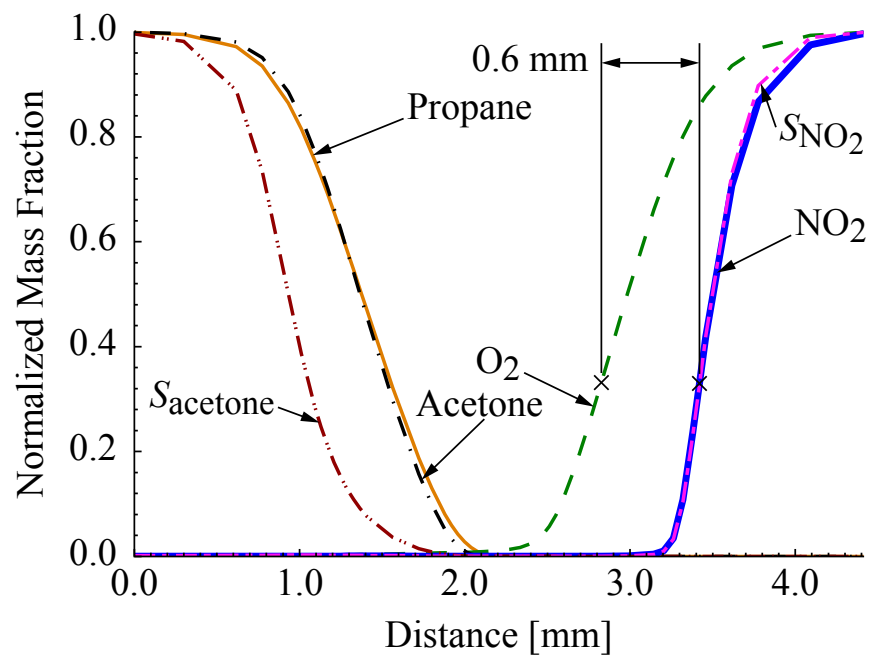

(b) Non-premixed CHEMKIN computation.

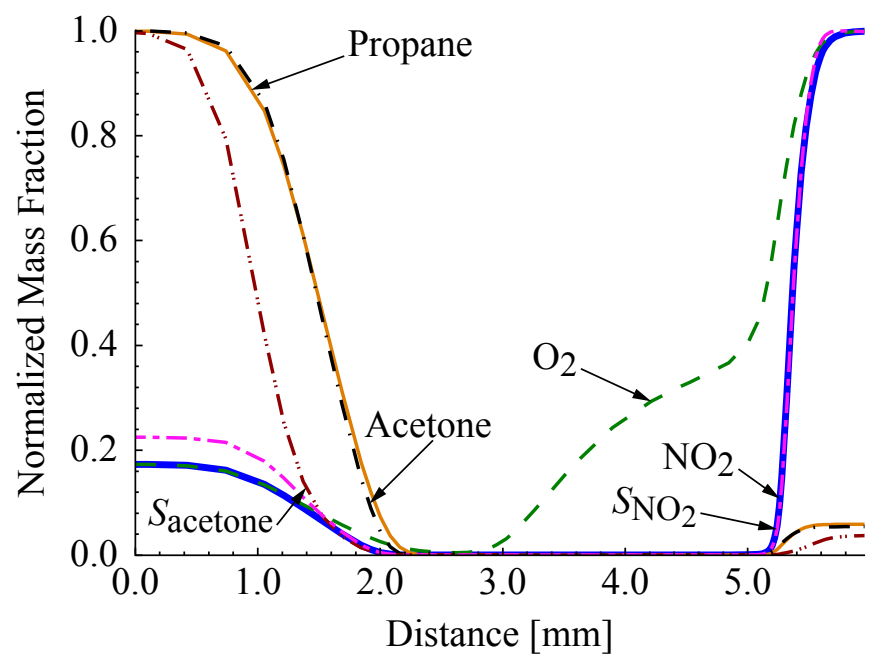

(c) Partially-premixed CHEMKIN computation.

Fig. 1. CHEMKIN computations that demonstrate that the actual flame index (Eq.1) equals the measured flame index (Eq. 8) for three laminar cases: premixed, non-premixed and partially-premixed. The partially-premixed case (c) has $75 \%$ fuel and $25 \%$ air on one side; it has $97 \%$ air, $3 \%$ fuel on the other side. 
Table 1

Values of maximum gradients associated with the computed profiles plotted in Figs. 1a, 1b, and 1c. Actual flame index is $\frac{\nabla Y_{\mathrm{F}, \max } \cdot \nabla Y_{\mathrm{O}, \max }}{\left|\nabla Y_{\mathrm{F}, \max } \cdot \nabla Y_{\mathrm{O}, \max }\right|}$ while measured flame index is $\frac{\nabla S_{\text {acetone,max }} \cdot \nabla S_{\mathrm{NO}_{2}, \text { max }}}{\left|\nabla S_{\text {actone,max }} \cdot \nabla S_{\mathrm{NO}_{2}, \text { max }}\right|}$. In all cases, the actual and measured flame indices are equal.

\begin{tabular}{|c|c|c|c|c|c|c|}
\hline Case & $\begin{array}{l}\nabla Y_{\mathrm{F}, \max } \\
{\left[\mathrm{mm}^{-1}\right]}\end{array}$ & $\begin{array}{l}\nabla Y_{\mathrm{O}, \max } \\
{\left[\mathrm{mm}^{-1}\right]}\end{array}$ & $\begin{array}{c}\nabla Y_{\text {acetone, } \max } \\
{\left[\mathrm{mm}^{-1}\right]}\end{array}$ & $\begin{array}{c}\nabla Y_{\mathrm{NO}_{2}, \max } \\
{\left[\mathrm{mm}^{-1}\right]}\end{array}$ & $\begin{array}{c}\text { Actual } \\
\text { flame index }\end{array}$ & $\begin{array}{l}\text { Measured } \\
\text { flame index }\end{array}$ \\
\hline Premixed & -4.3 & -1.8 & -2.8 & -4.7 & +1 & +1 \\
\hline Non-premixed & -1.0 & 1.1 & -1.5 & 2.4 & -1 & -1 \\
\hline Partially-premixed & -0.9 & 1.5 & -1.1 & 4.2 & -1 & -1 \\
\hline
\end{tabular}

The normalized Boltzmann fraction $\left(f / f_{\text {ref }}\right)$ is a function of the gas temperature and the rotational moment of inertia of the $\mathrm{NO}_{2}$ molecule, which is given in the textbook by Hertzberg [45]. The Einstein coefficient, $A_{j k}$, is known to be small with respect to $Q$ at atmospheric pressures, but it was included. The quenching factor, $Q$, is proportional to the total quenching cross section that is based on the known cross sections of $\mathrm{N}_{2}, \mathrm{O}_{2}, \mathrm{CO}_{2}, \mathrm{H}_{2} \mathrm{O}, \mathrm{CH}_{4}$, and $\mathrm{C}_{3} \mathrm{H}_{8}$, and their CHEMKIN mole fractions.

Figure 1 is a plot of the resulting profiles for three cases: a fully premixed flamelet, a fully non-premixed flamelet (between pure fuel and pure air), and a partially-premixed flamelet. The latter has $25 \%$ air mixed with $75 \%$ fuel on the fuel-rich side. The fuel-lean side has $3 \%$ fuel mixed in with $97 \%$ air. These two mixtures are not flammable so the partially-premixed case is computed using the CHEMKIN diffusion flame solver. If the mixture on either side enters the flammable regime, a premixed flame results.

First it is noted that the goal is not to expect that the magnitude of the fluorescence signal in Fig. 1 will match the magnitude of the fuel (or $\mathrm{O}_{2}$ ) mass fraction at every location because the magnitude of the signal is not used in any part of the measurement of flame index. Only the sign of the maximum gradient is important (i.e., whether the sign of the gradient is positive or negative). That is, all magnitudes are removed in Eq. (1) because the numerator is normalized by its magnitude, so the resulting flame index is a number that is either $+1,-1$, or zero. What is important is that the signs of the gradients of the tracer signals match the signs of the gradients of the corresponding mass fractions. Thus the goal was to assess the accuracy of making the following approximation:

$$
\frac{\nabla Y_{\mathrm{F}, \max } \cdot \nabla Y_{\mathrm{O}, \max }}{\left|\nabla Y_{\mathrm{F}, \text { max }} \cdot \nabla Y_{\mathrm{O}, \max }\right|}=\frac{\nabla S_{\text {acetone,max }} \cdot \nabla S_{\mathrm{NO}_{2}, \max }}{\left|\nabla S_{\text {acetone,max }} \cdot \nabla S_{\mathrm{NO}_{2}, \max }\right|} .
$$

There are two issues of importance; since the left side of Eq. (8) takes on only the values of +1 , -1 , or zero for a given flamelet, it is desired that the right side take on the same value. The second issue is that the location in space where the left side is +1 , for example, may differ from the location where the right side takes on this value.

First consider CHEMKIN profiles in Figs. 1a-c. The profile of acetone mass fraction lies directly on top of that profile of propane mass fraction in all three figures. Propane and acetone have nearly the same mass diffusivity and both decompose at approximately the

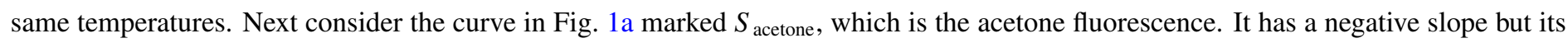
slope is different from the slope of the propane curve. The short black lines mark the maximum gradients. The maximum gradients in the propane and $\mathrm{O}_{2}$ mass fractions and in acetone and $\mathrm{NO}_{2}$ signal are: $-4.3 \mathrm{~mm}^{-1},-1.8 \mathrm{~mm}^{-1},-2.8 \mathrm{~mm}^{-1}$, and $-4.7 \mathrm{~mm}^{-1}$, respectively. Table 1 shows that the value of the actual flame index and the measured flame index are both +1 for this premixed example.

It is noted that the profile of acetone signal in Fig. 1a is displaced from the propane curve by a very small distance of $0.1 \mathrm{~mm}$. This displacement arises because of Eq. (6); the acetone fluorescence yield decreases with temperature based on the data of Thurber and Hanson [28]. The displacement creates an uncertainty in the location of the flamelet, however its value of $0.1 \mathrm{~mm}$ is smaller than the spatial resolution of the measurements. The displacement has no effect on the primary measurement of interest-the fraction of flamelets that are premixed-since the location of each flamelet is not relevant after spatial averaging is performed. 
The non-premixed row in Table 1 shows the maximum gradients of the profiles in Fig. $1 \mathrm{~b}$. Table 1 shows that the actual and measured values of flame index both are -1 . For the non-premixed case there is a gap between the locations of the maximum gradients in fuel and $\mathrm{O}_{2}$. The gap arises because both species decompose as they enter the reaction zone. This presents no problem; we adopt the same procedure that has been used in previous DNS studies. For each pixel in the image that is associated with a large fuel gradient, a search is conducted to find the nearest $\mathrm{O}_{2}$ gradient. If the two gradients are sufficiently close to each other, the two maximum gradient values are multiplied to form the numerator of Eq. (1).

An example of a partially-premixed case appears in Fig. 1c. On both sides of the flamelet there exist fuel- $\mathrm{O}_{2}$ mixtures, but on neither side is the mixture in the flammable range, which typically extends between equivalence ratios of 0.5 to 2.0 . So premixed combustion is not possible and this partially-premixed flame is a type of diffusion flame. That is, it is not a wave that propagates as does a premixed flame. Since it is diffusion-dominated, it should have a flame index of -1 . The partially-premixed row in Table 1 shows the values of the maximum gradients of the profiles in Fig. 1c; both the actual and measured (marker gas) gradients yield a flame index of -1 . It is concluded that the correct value of flame index (either $+1,-1$, or zero) can be measured from the tracer gas profiles for all three cases in

Fig. 1. However, there is a small uncertainty in the location of each flamelet that varies from negligible $(0.1 \mathrm{~mm})$ in the premixed case to approximately $0.6 \mathrm{~mm}$ for a non-premixed case.

There is a known ambiguity that can arise due to the definition of the Takeno flame index. Note that in Fig. 1c there are two gradients of the $\mathrm{O}_{2}$ mass fraction because both fuel and air exist on the fuel-rich side. In Fig. 1c there is no problem in computing a flame index of -1 because the gradient in $\mathrm{O}_{2}$ mass fraction is much larger on the right side than on the left side. Our search algorithm would correctly select the larger gradient on the left side rather than the much smaller gradient of $\mathrm{O}_{2}$ on the left side. However, if a larger amount of air were to be mixed on the fuel side there could be two equally large gradients of $\mathrm{O}_{2}$ and the Takeno flame index could be either +1 or -1 , depending on which of the two $\mathrm{O}_{2}$ gradients is selected. This is not a problem associated with the diagnostics because the diagnostics will correctly identify both $\mathrm{O}_{2}$ gradients. Instead it is an ambiguity associated with the definition of the Takeno flame index. To resolve this issue - which will arise in both DNS and in experiments - it is best to first identify any locations where two large gradients in $\mathrm{O}_{2}$ may occur, then consider the Takeno flame index to be undefined at those locations. Other definitions of flame index can avoid this ambiguity, but they require measurement of local reaction rate, which is not yet possible.

\section{Experimental approach}

\subsection{Planar laser-induced fluorescence (PLIF) system}

The acetone in the fuel was excited with an Nd:YAG laser operated at a wavelength of $266 \mathrm{~nm}$ in a manner similar to that of previous studies [28, 31-34]. The $8 \mathrm{~mm}$ tall light sheet has an energy of $10 \mathrm{~mJ} /$ pulse. Fluorescence in the range from $300 \mathrm{~nm}$ to $320 \mathrm{~nm}$ passed through an Omega Optical 500ASP filter and was collected using a Micro-Nikkor 105mm f/2.8D lens. The ICCD camera (Andor iStar DH734-25F-03) that recorded the acetone signal was blue-sensitive. Simultaneous $\mathrm{NO}_{2}$ fluorescence was excited by an Nd:YAG laser (Spectra Physics LAB-150) operated at $532 \mathrm{~nm}$ and $45 \mathrm{~mJ} /$ pulse, as has been done in previous studies [37, 38, 43, 44]. NO 2 fluorescence in the range from $600 \mathrm{~nm}$ to $800 \mathrm{~nm}$ was collected by a red-sensitive ICCD camera (Andor iStar DH334T-18U-A3) that was fitted with an interference filter (CVI Melles Griot LPF-600) and two 3 mm-thick color filters (Schott OG-550). To avoid observing the acetone fluorescence with the $\mathrm{NO}_{2}$ camera, the $266 \mathrm{~nm}$ laser was fired $500 \mathrm{~ns}$ prior to the $532 \mathrm{~nm}$ laser. For each camera, the intensifier was gated to open $50 \mathrm{~ns}$ before the firing of the laser and the gate remained open for $100 \mathrm{~ns}$.

The spatial resolution of the diagnostics in the direction normal to the light sheet was the sheet thickness of $130 \mu \mathrm{m}$ that was measured using a traversing a knife edge. Resolution in the plane of the light sheet was set to $86 \mu \mathrm{m}$ by binning and averaging each set of 4 pixels by 4 pixels. The spatial resolution is approximately one-sixth the thickness of a laminar premixed flamelet and is one-nineteenth the thickness of a laminar non-premixed flamelet, based on CHEMKIN calculations and calibration flame data in the next section. The two 
PLIF signals were found to have a linear dependence on both the gas concentration (of acetone and $\mathrm{NO}_{2}$ ) as well as on the laser energy per pulse [46]. This is consistent with the PLIF calibration data reported in Refs. [28, 35, 38, 40].

The signal-to-noise ratio (SNR) was measured by recording the signals in a region of pure fuel-acetone mixture and in a region containing a pure air- $\mathrm{NO}_{2}$ mixture. The value of the standard deviation of the signal in these regions was defined to be the noise in the acetone and $\mathrm{NO}_{2}$ LIF signals, respectively. The signal-to-noise ratio of the acetone PLIF was measured to be 24 while for the $\mathrm{NO}_{2} \mathrm{PLIF}$ it was 13.

For each run condition 450 PLIF image pairs were acquired. The images from the two cameras were registered and de-warped using a target grid that consists of a thin piece of glass $50 \mathrm{~mm}$ by $50 \mathrm{~mm}$ that was mounted on a 3-D micrometer mount. The grid was located where the two laser sheets overlaped and it was etched with lines that were $150 \mu \mathrm{m}$ thick. Prior to each run, images of the target grid from each camera were input into commercial software that scaled and registered the two sets of images. Before and after each run several sets of background images were recorded. The different sets corresponded to: laser on and laser off, flame on and flame off, and acetone and $\mathrm{NO}_{2}$ on and off.

Dark noise was subtracted, as well as the background signals from flame luminosity and from scattered laser light that was not rejected by optical filters. These contributions were measured to be less than $5 \%$ of the signal and were subtracted using several formulas that were derived by Clemens [47]. Flame luminosity was reduced to negligible levels by setting the camera exposure time to $100 \mathrm{~ns}$. The time between when the two lasers were fired was set to $500 \mathrm{~ns}$ to avoid interferences. In addition, all images were corrected for $20 \%$ variations in laser intensity across the sheets. About $10 \%$ of the sheet energy was split off of both laser sheets, and was directed into a dye cell. For each laser pulse a camera recorded an image of the lines of fluorescence from the dye and this profile was used to normalize each image. Camera pixel sensitivity variations were measured by exposing the cameras to a uniform white field; all images were normalized by this image. More details are provided in the thesis work listed as Ref. [46]. A non-linear anisotropic diffusion filter (NADF) [48] was applied to remove additional noise; it resists any smoothing of the data across regions of large gradients. Thus additional noise is removed while the desired large-scale gradients are resolved and spatial resolution is altered. Appendix A describes the calibration experiments that were run to insure that the $\mathrm{NO}_{2}$ PLIF signals were linear functions of the tracer gas concentration and the laser energy.

\subsection{Data analysis procedures}

To determine the flame index, four steps were taken to analyze the PLIF images. First the locations were identified where the gradients exceed a threshold value. The second step was to conduct a search in space, starting from an acetone gradient layer, to find the nearest $\mathrm{NO}_{2}$ gradient layer. Then it was determined if the two gradient directions are aligned, which is an indicator of premixed combustion. In the final step the non-premixed flamelets were separated from non-reacting mixing layers.

The first step was to remove noise from the PLIF images by using a central-differencing method to compute gradients, then a Canny edge detection algorithm [49] was applied. Gradients due to noise are uncorrelated in space and were discarded while gradients due to flamelets are correlated in space and formed layers that remained in the images.

The next step was to conduct a search to match each acetone gradient layer with its nearest $\mathrm{NO}_{2}$ gradient layer. Starting in one corner of the image, a pixel in an acetone layer was identified along with the direction of the acetone gradient. The search proceeded down the gradient along the gradient direction for $1.0 \mathrm{~mm}$ or until an $\mathrm{NO}_{2}$ gradient layer was detected. The search was always conducted for $0.5 \mathrm{~mm}$ in the other direction as well. If no $\mathrm{NO}_{2}$ layer was detected, no flamelet existed at that location and the pixels were assigned a flame index of zero.

The third step was to examine the adjacent gradient layers that were identified in the previous step and determine if a premixed flamelet exists. Values of the gradients were inserted into Eq. (8). If the resulting value of $\xi$ was equal to +1 then the layer must have 


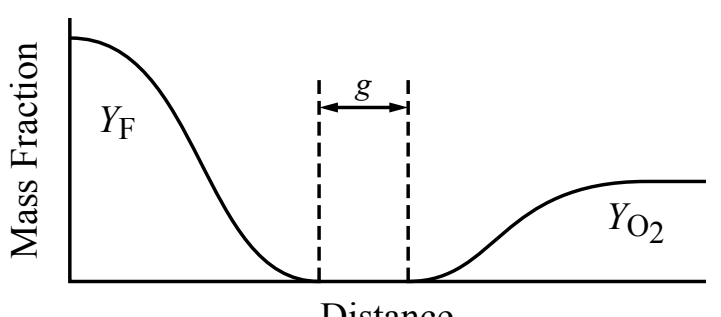

(a) Reacting.

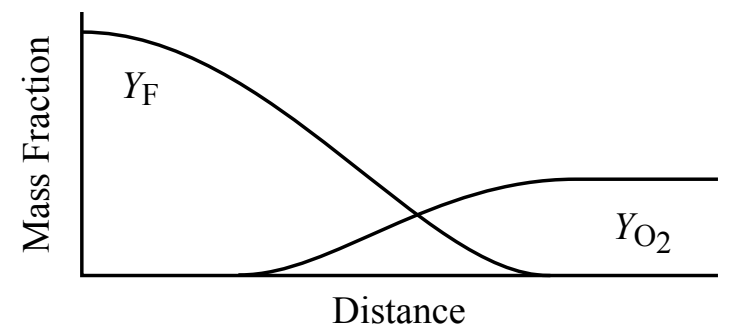

(b) Non-reacting.

Fig. 2. Gap $(g)$ must exceed $0.13 \mathrm{~mm}$ to identify a non-reacting mixing layer shown in (a) the reacting case. Gap $(g)$ will be zero for situation (b), a non-reacting mixing layer.

been a premixed flamelet and it cannot be a non-reacting mixing layer. That is, if fuel and $\mathrm{O}_{2}$ were mixing with no reaction, the profiles would look similar to those drawn in Fig. 2b. The fuel and $\mathrm{O}_{2}$ mass fraction profiles could not both be decreasing in the direction normal to the flamelet if there were no reactions present. All the pixels in the gradient layer that met these premixed criteria were assigned a flame index value of +1 .

The final step was to distinguish a non-premixed flamelet, sketched in Fig. 2a, from a non-reacting mixing layer, sketched in Fig. $2 b$. Both have gradients in fuel and $\mathrm{O}_{2}$ that are in opposite directions. However, a non-premixed flamelet must have a gap between the fuel and $\mathrm{O}_{2}$ profiles, as is seen in Fig. 2a, which is a schematic representation of CHEMKIN results in Fig. 1b. The gap occurs because both pure fuel and $\mathrm{O}_{2}$ decompose due to chemical reactions before they can overlap. However, in the non-reacting mixing layer drawn in Fig. $2 b$, the fuel and $\mathrm{O}_{2}$ profiles do not display a gap between the profiles.

The critical value of the gap size, $g$, was selected to be $0.13 \mathrm{~mm}$, which is the spatial resolution of the measurements and is the smallest gap size measurable. Therefore for cases for which the acetone and $\mathrm{NO}_{2}$ PLIF gradients were in the opposite direction, if a gap exceeding $0.13 \mathrm{~mm}$ was measured between the profiles, the layer was determined to be a non-premixed flamelet and the value of $\xi$ for all pixels in the layer was set to -1 . Otherwise, the layer was determined to be a non-reacting mixing layer and $\xi$ was set to zero. The effects of this gap criterion are described in Appendix B. A few layers that have no gap are circled in the image that is shown in Appendix B; these layers are non-reacting layers and were discarded.

\subsection{Laminar flame calibration experiments and uncertainty analysis}

Both laminar premixed and non-premixed flames were investigated before attempting the turbulent flame measurements that are described in Section 5. A premixed laminar flame was stabilized above an $8 \mathrm{~mm} \mathrm{~mm}$ diameter tube through which flowed a fuelacetone-air- $\mathrm{NO}_{2}$ mixture. The tube was surrounded by low-velocity co-flowing air. Equivalence ratios were set to 0.8 and 1.2. Then the same co-flow burner was used to stabilize a laminar non-premixed flame by flowing only a fuel-acetone mixture through the tube.

Figure 3 contains typical profiles of $\mathrm{NO}_{2}$ and acetone signals. For the premixed case in Fig. 3a the two normalized signals closely overlap, while for the non-premixed case in Fig. $3 \mathrm{~b}$ a gap is seen between the two profiles. This gap does not occur when non-reacting flows undergo fuel-air mixing, as was illustrated in Fig. 2. The trends in the measured profiles in Fig. 3 are in agreement with the 


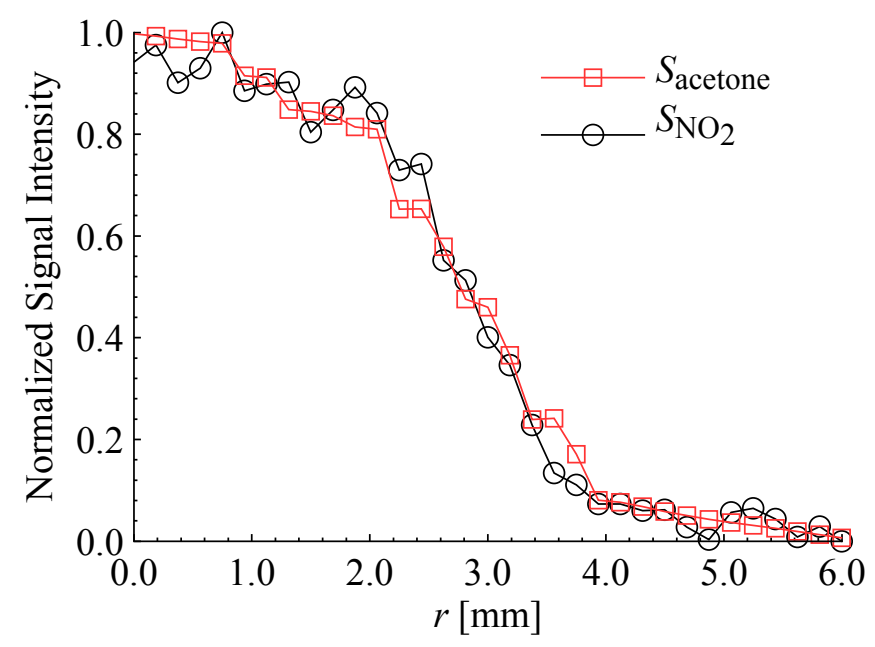

(a) Premixed.

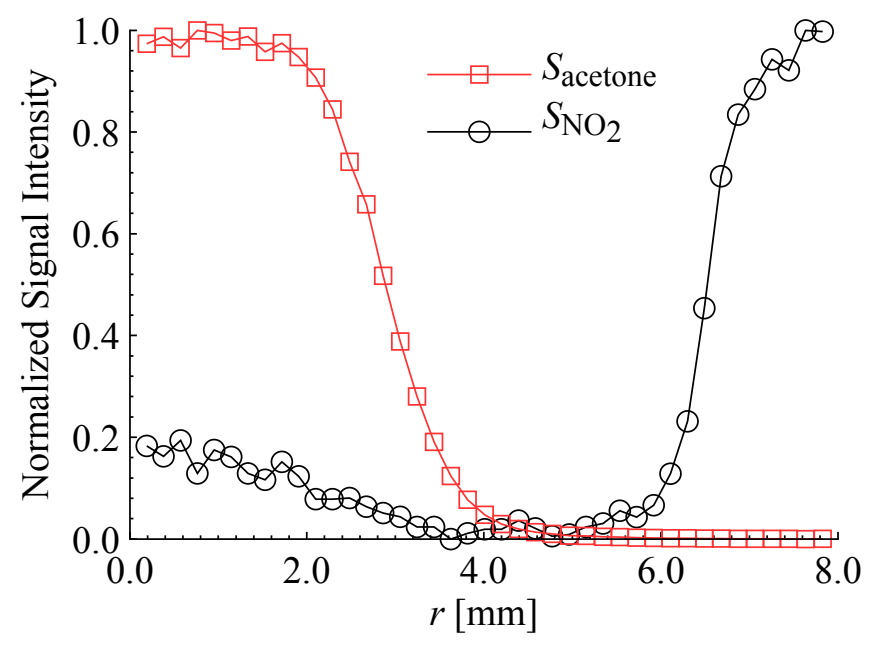

(b) Non-premixed.

Fig. 3. Measured profiles of $\mathrm{NO}_{2}$ and acetone PLIF signals within the laminar calibration flames; (a) premixed and (b) non-premixed cases.

computed CHEMKIN profiles in Fig. 1, but obtaining quantitative agreement was not a goal because the strain rates on the experimental laminar flames are not known. Figure 3 indicates that our spatial resolution of $130 \mu \mathrm{m}$ is sufficient to resolve the scalar gradients of interest.

An uncertainty analysis was performed that is only summarized here; it is described in more detail in the Ph.D. thesis of the first author [46]. Five potential sources of error were identified.

(a) Premixed flamelets could be incorrectly measured to be non-premixed (and vice versa).

(b) There is an uncertainty in the location of each layer.

(c) An averaging error could arise due to averaging over 450 images rather than a larger number of images.

(d) Flamelets can exist that are not detected.

(e) Non-reacting mixing layers may be incorrectly identified as flamelets. 
For the laminar calibration flame measurements there was less than a $2 \%$ uncertainty associated with the first three sources (a), (b), and (c). Of course, in a turbulent flame the uncertainties could be expected to be larger than in the laminar experiment. Error (a) arises if a premixed flame is incorrectly identified as being non-premixed. At more than 1000 locations in the laminar premixed calibration experiment the measured value of flame index, $\xi$, was always +1 . It was never incorrectly measured to be -1 . Similarly, at 1000 locations in the laminar non-premixed experiment the value of $\xi$ was always measured to be -1 . This indicates that the signal-to-noise ratio was sufficiently large that in the laminar calibration flame there was a negligible probability — of less than $1 \%$ - that a gradient in the fuel or $\mathrm{O}_{2}$ was measured to be in a direction that is opposite to the true direction.

Error (b) is the uncertainty in measuring the locations of flamelets. The only way to estimate this error is from the CHEMKIN profiles in Fig. 1. They showed that there was a small shift of $0.1 \mathrm{~mm}$ between the location of the true center of a premixed flamelet and that deduced from PLIF. For a non-premixed flamelet, the shift is $0.6 \mathrm{~mm}$. This small uncertainty has a negligible effect on the spatially-averaged values of flame index and the fraction of flamelets that are premixed.

Error (c) is the statistical uncertainty due ensemble-averaging of 450 images rather than a larger number of images. Statistical uncertainty is defined to be the mean determined from $N$ images minus the mean expected by using an infinite number of images, after normalizing by the measured mean. The standard relation for the $98 \%$ confidence interval is $2.33\left(\sigma_{\xi} / \bar{\xi}\right) / \sqrt{N}$. The typical normalized standard deviation $\left(\sigma_{\xi} / \bar{\xi}\right)$ was measured to be 0.2 so this relation yields a statistical uncertainty of $2 \%$. Therefore there is no need to average over more than 450 images.

Error (d) arises if flamelets exist but they are not detected. Several thousand locations were selected within many images of the two laminar calibration flames. Since about $80 \%$ of the flamelets in the turbulent swirl flame experiment were premixed and $20 \%$ were nonpremixed, the overall error was estimated to be 0.8 times the fraction of premixed (laminar) flames that are not correctly recorded plus 0.2 times the fraction of non-premixed (laminar) flames that are not correctly recorded. Based on this weighting criterion, approximately $6 \%$ of the flamelets that exist in the laminar flames were not detected by the diagnostics. The reason is that the PLIF signal-to-noise ratio causes statistical fluctuations in the signal. Uncertainties can be reduced by increasing the signal-to-noise level, which requires more powerful lasers, larger collection lenses, or more $\mathrm{NO}_{2}$ addition to the air.

Another source of uncertainty is the three-dimensional nature of the flame. The present images are two-dimensional, as are almost all previously-reported images of flame structure. However, there is no reason to believe that the quantity of interest (the statistical average of the fraction of flamelets that are premixed) within our dataset of 2-D images should differ significantly from the true 3-D average.

\subsection{Gas Turbine Model Combustor}

It was decided to make flame index measurements in the well-characterized partially-premixed combustor that is shown in Fig. 4, the Gas Turbine Model Combustor (GTMC) that was designed by Meier and colleagues at DLR, Stuttgart [26, 27, 50, 51]. The present burner was constructed from the DLR drawings; the dimensions are given by Wiegand et al. [50]. The GTMC injector consisted of a central air nozzle, an annular fuel nozzle and an outer co-annular air nozzle. The inner air nozzle had an outer diameter of 15 mm; the outer air flow had an inner diameter of $17 \mathrm{~mm}$ and an outer diameter of $25 \mathrm{~mm}$. Swirl was added to both the inner and outer air flows, which were at atmospheric pressure and temperature. The swirl number was approximately 0.55 [50]. No swirl was added to the fuel. The combustion chamber had a square cross section of $85 \mathrm{~mm}$ in width and $110 \mathrm{~mm}$ in height. The four sidewalls were fused silica windows that provided optical access.

Acetone was added by bubbling the propane through a temperature-controlled tank containing liquid acetone. Vapor pressure curves and a secondary propane dilution line were used to determine that the volume fraction of acetone vapor was $21 \%$ in the fuel stream. Compressed air tanks were purchased that contained $5000 \mathrm{ppm}$ of $\mathrm{NO}_{2}$ in air.

The three operating conditions (P-1, P-2, and P-3) are listed in Table 2. The total mass flow rate was varied, as well as the velocity 


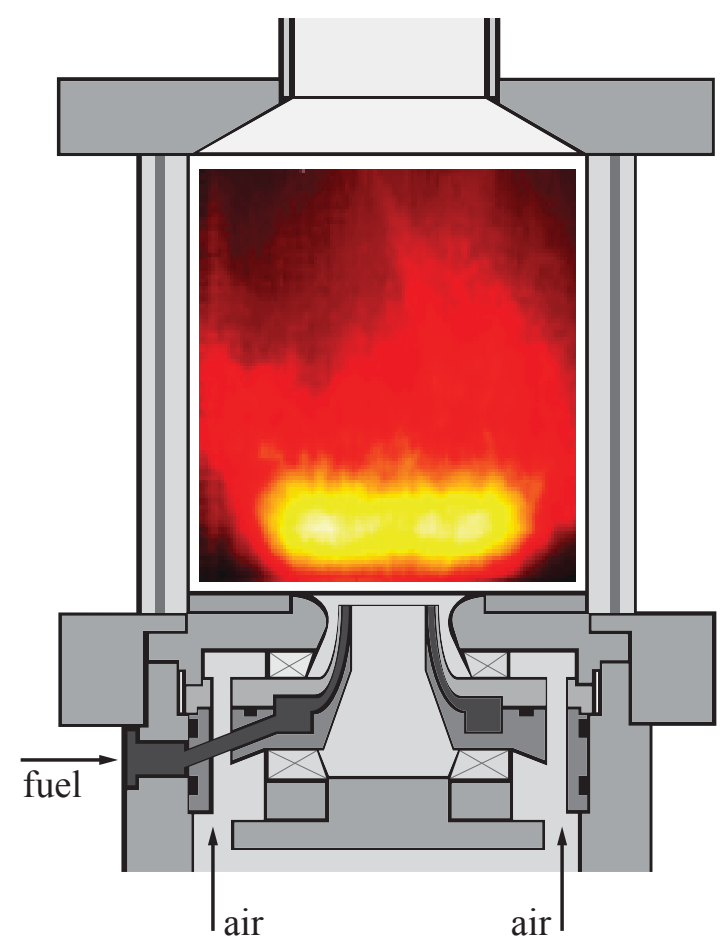

Fig. 4. Schematic of the DLR gas turbine model combustor [50] along with a digitized image of the chemiluminescence.

Table 2

Operating conditions for the three cases of partially-premixed combustion in the GTMC burner. For all cases: fuel was $79 \%$ propane and $21 \%$ acetone by volume. The air contained $5000 \mathrm{ppm} \mathrm{NO}_{2}$.

\begin{tabular}{cccccc}
\hline \hline Case & $\dot{m}_{\mathrm{a}}[\mathrm{g} / \mathrm{min}]$ & $\dot{m}_{\mathrm{f}}[\mathrm{g} / \mathrm{min}]$ & $\phi_{\text {global }}$ & $V R$ & $\beta$ \\
\hline $\mathrm{P}-1$ & 173 & 15.0 & 1.20 & 0.47 & 0.79 \\
$\mathrm{P}-2$ & 302 & 26.6 & 1.21 & 0.47 & 0.78 \\
$\mathrm{P}-3$ & 300 & 16.9 & 0.77 & 0.30 & 0.74 \\
\hline \hline
\end{tabular}

ratio $(V R)$, in order to see how the flame index depended on these two governing parameters. Velocity ratio is defined to be:

$$
V R=\frac{u_{y, \text { fuel }}}{u_{y, \text { air }}}
$$

The vertical velocities, $u_{y}$, in Eq. (9) are spatially-averaged values because they were determined from the mass flow rates of fuel and air. P-1 is the baseline case that has a lower air flow rate than the other two cases. Case P-2 has the same velocity ratio as P-1 but has about twice the air flow rate. Case P-3 has the same large flow rate as P-2 but has a lower velocity ratio. The fuel-air equivalence ratios, $\phi$, for cases P-1, P-2, and P-3 were: 1.20, 1.21, and 0.77. The power output was $11 \mathrm{~kW}$ for cases P-1 and P-3 and was $20 \mathrm{~kW}$ for case P-2. Care was taken to run the burner for a sufficiently long warm-up time to insure that the measured burner wall temperature reached the same value for each run.

\section{Results}

\subsection{Instantaneous images}

Figure 5 displays typical simultaneous images of $\mathrm{NO}_{2}$ and acetone. The fuel jet in Fig. $5 \mathrm{~b}$ is seen to be thrown radially outward by the centrifugal forces imparted by the swirling air. The fuel is surrounded on both sides by the inner and the outer swirling air seen 


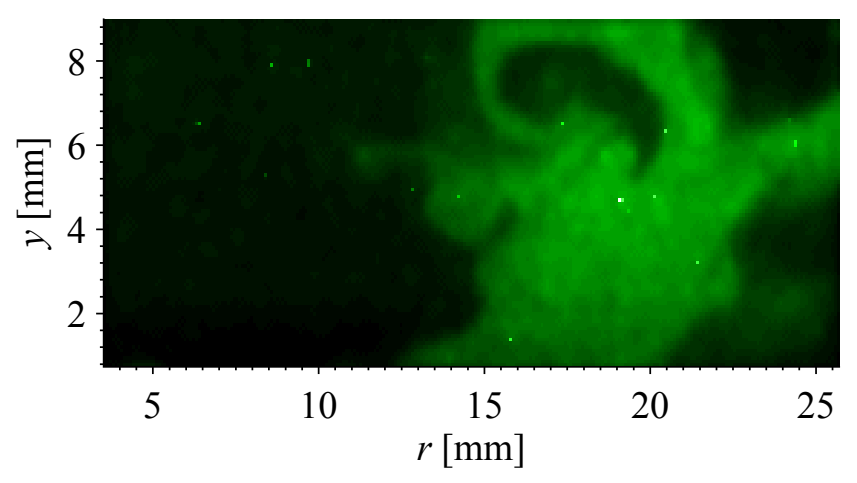

(a) $\mathrm{NO}_{2}$ PLIF image.

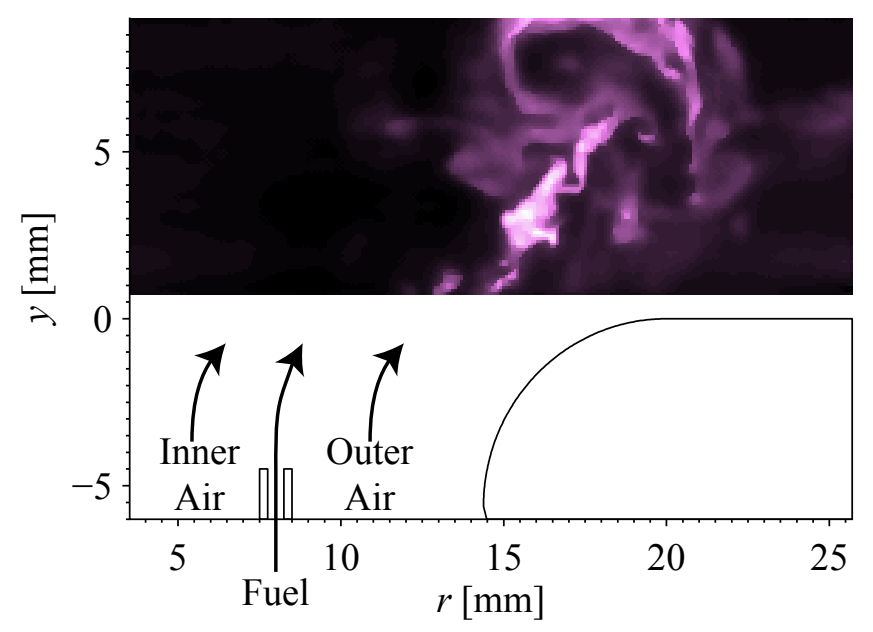

(b) Acetone PLIF image.

Fig. 5. Simultaneous (a) $\mathrm{NO}_{2}$ and (b) acetone PLIF images from case P-3. The burner centerline is located at $r=0 \mathrm{~mm}$, while the burner exit plane is located at a height of $y=0 \mathrm{~mm}$. The field of view is $8 \mathrm{~mm}$ by $23 \mathrm{~mm}$.

in Fig. 5a. The inner boundary of the air region is the central recirculation zone that is filled with products. A large rotational region appears near the top of Figs. $5 \mathrm{a}$ and $5 \mathrm{~b}$ at this instant in time.

Two instantaneous images of flame index are shown in Fig. 6 and other instantaneous flame index images appear in Fig. 7. The centerline of the fuel injector is located at $r=0 \mathrm{~mm}$, to the left of each image. The annular fuel port is also drawn. Red-colored pixels are used to indicate the center of each wrinkled premixed flamelet. Dark blue pixels indicate non-premixed flamelets. It is observed that all of the flamelets are thin and have thicknesses of less than $1.5 \mathrm{~mm}$, which is consistent with the computations displayed in Fig. 1.

To better understand the flame structure, notice that there are three figures that contain the same instantaneous images that are plotted in different ways. Figure 5 displays the acetone and $\mathrm{NO}_{2}$ signals separately while Fig. 6a is the resulting flame index. In Fig. 8a the flame index is shown overlapping the $\mathrm{NO}_{2}$ signal, while in Fig. $8 \mathrm{~b}$ flame index overlaps the acetone signal. Notice that in all of these figures there is a large vortex-like pattern associated with both the fuel and the air. The vortex-like patterns seen in Figs. 5a and $5 \mathrm{~b}$ are similar, indicating that the fluid in this vortex pattern is significantly premixed. This explains why many of the flamelets seen in Fig. 6a are of the premixed type. Figure 8 a shows the $\mathrm{NO}_{2}$ signal with the flame index values overlapped. The vortex-like structure contains oxygen (as indicated by the $\mathrm{NO}_{2}$ signal) and there are large gradients at the edges of the structure. Similarly, Fig. $8 \mathrm{~b}$ displays the acetone signal with flame index values overlaid. The acetone signal often has large gradients exactly where the $\mathrm{NO}_{2}$ has large gradients, and both gradients point in the same direction, thus the flame index is +1 at those locations.

Some non-premixed flamelets also are displayed in Fig. 6a and they are plotted again in Fig. 8. Notice that in Fig. 8b the non- 


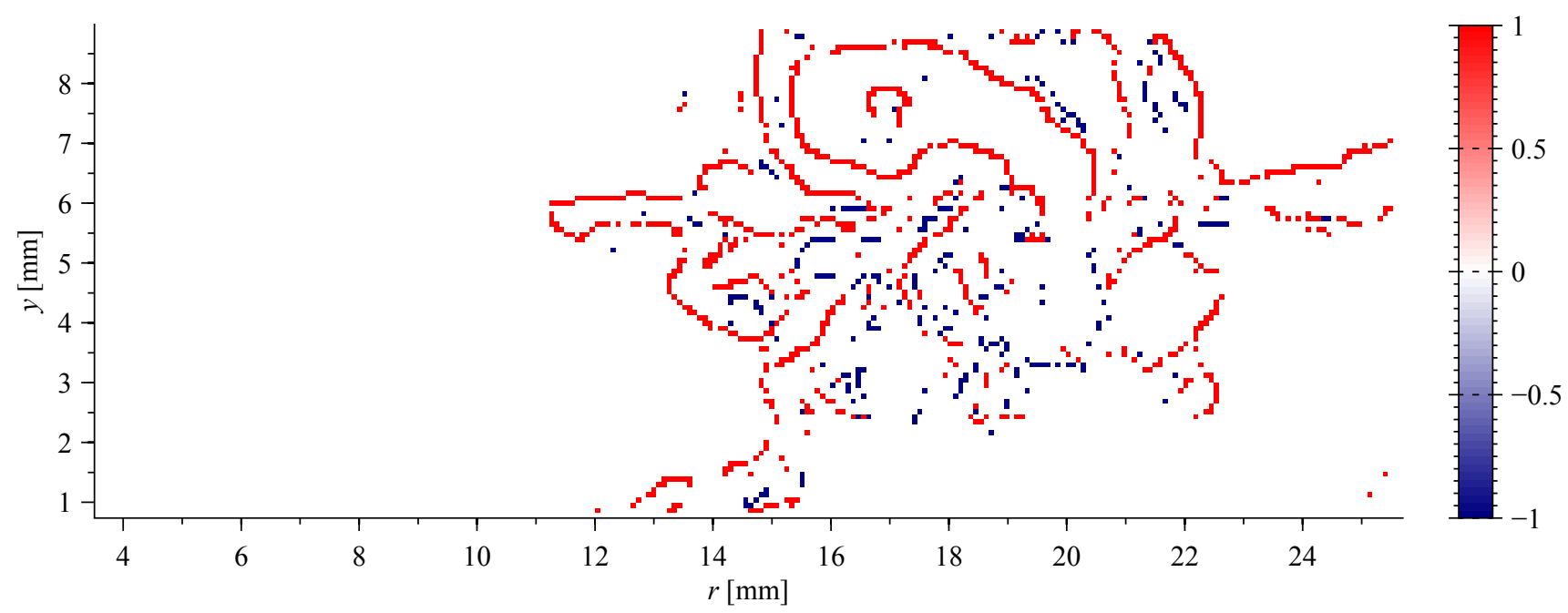

(a) Case P-3, fuel-lean equivalence ratio, high velocity ratio, and high flow rate. Flame index map for images shown in Fig. 5.

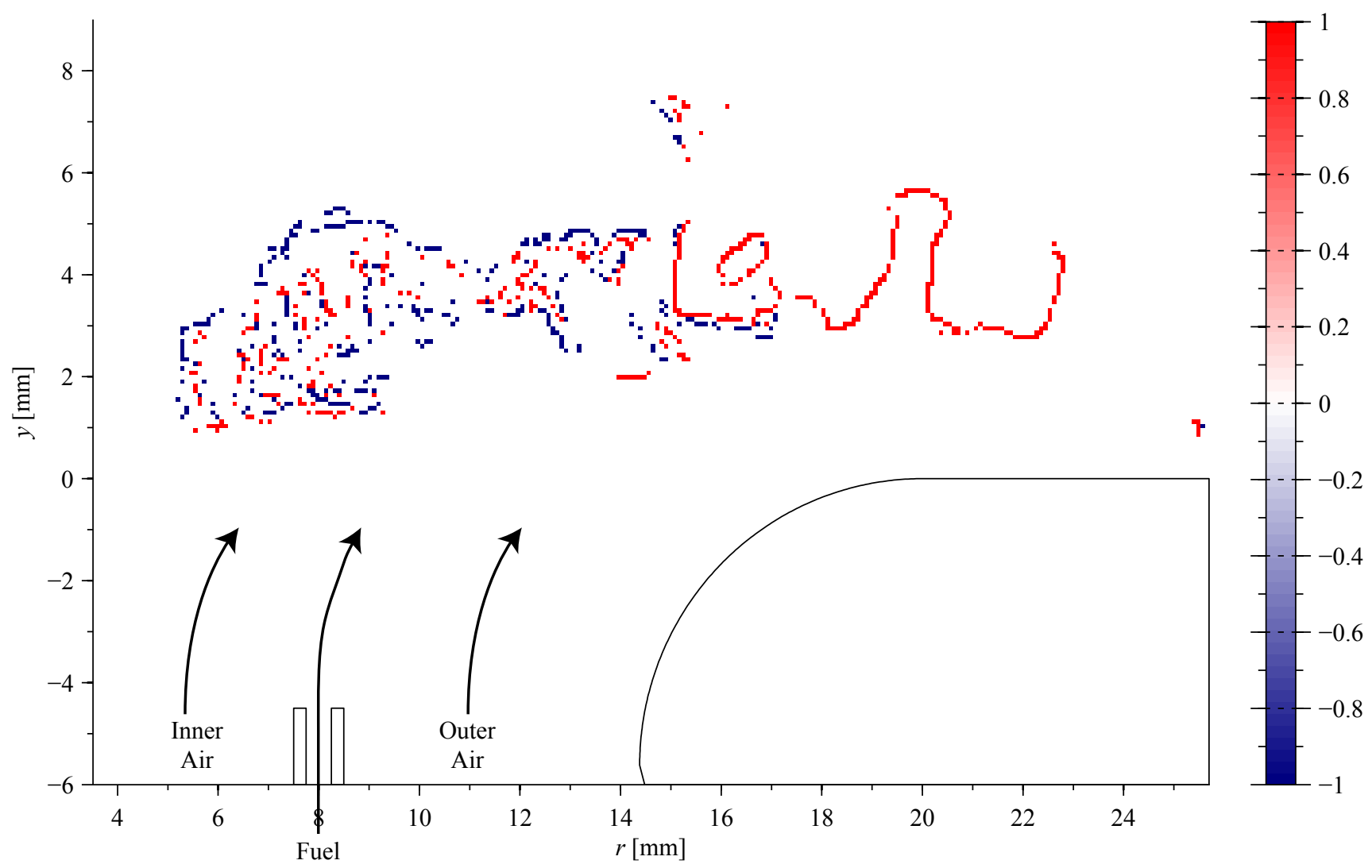

(b) Case P-3, fuel-lean equivalence ratio, high velocity ratio, and high flow rate.

Fig. 6. Two images of instantaneous flame index, $\xi$, in the GTMC burner. Non-premixed flamelets (dark navy blue) are more probable just above the fuel annulus, while premixed flamelets (red) are more probable downstream. The burner centerline is located at $r=0 \mathrm{~mm}$, while the burner exit plane is located at a height of $y=0 \mathrm{~mm}$. The field of view is $8 \mathrm{~mm}$ by $23 \mathrm{~mm}$. 


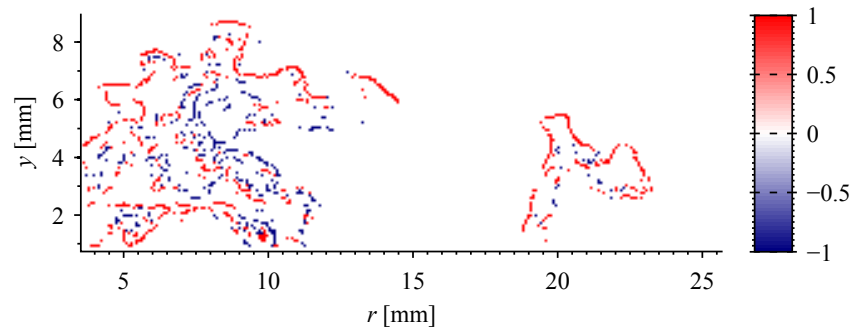

(a) Case P-3, fuel-lean equivalence ratio, high velocity ratio, and high flow rate.

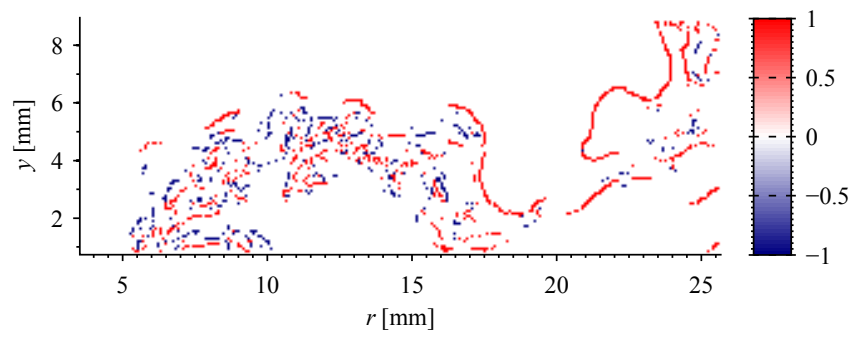

(b) Case P-3, when nearly $50 \%$ of flamelets are premixed.

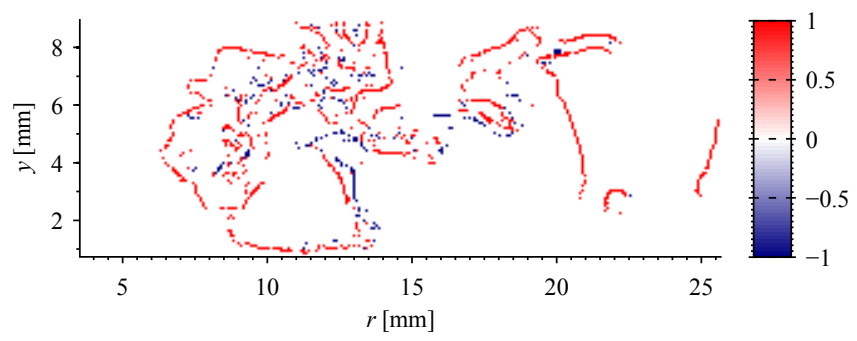

(c) Case P-3, when most flamelets are premixed.

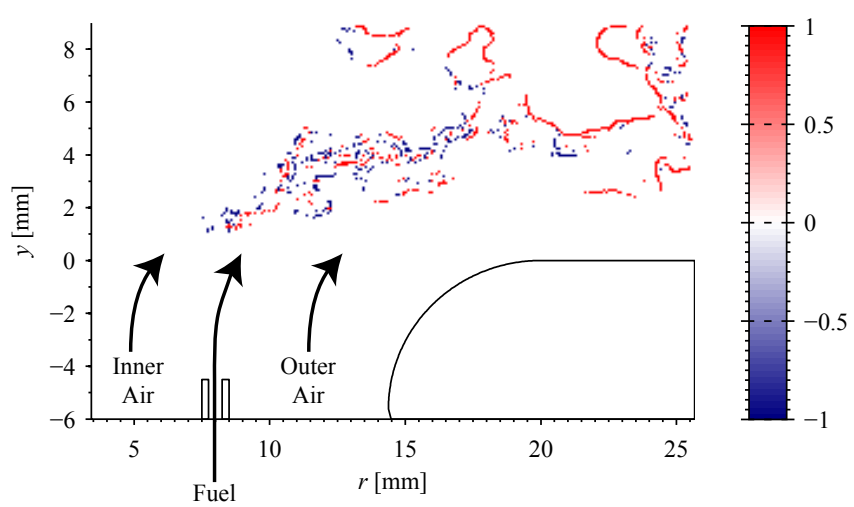

(d) Case P-2, fuel-rich equivalence ratio, high velocity ratio, and high flow rate.

Fig. 7. Additional images of instantaneous flame index, $\xi$, in the GTMC burner. Red indicates premixed flamelets and dark navy blue indicated non-premixed flamelets. The burner centerline is located at $r=0 \mathrm{~mm}$, while the burner exit plane is located at a height of $y=0 \mathrm{~mm}$. The field of view is $8 \mathrm{~mm}$ by $23 \mathrm{~mm}$. 


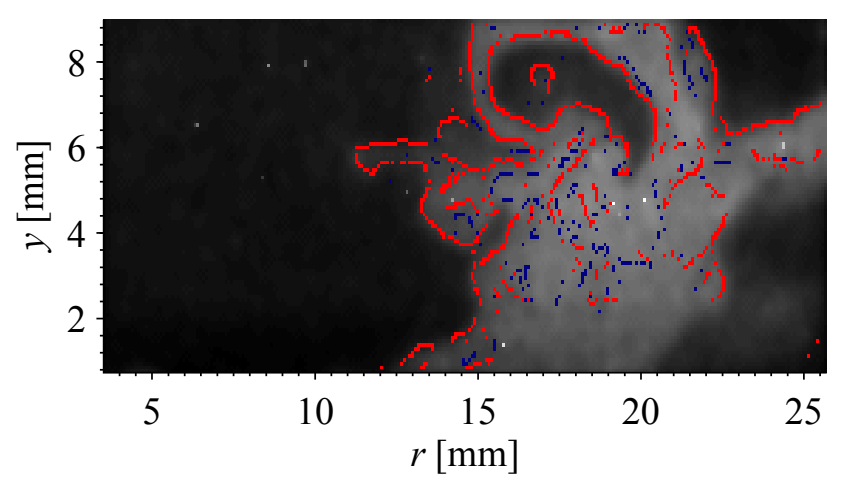

(a) $\mathrm{NO}_{2}$ PLIF image overlapped with $\xi$.

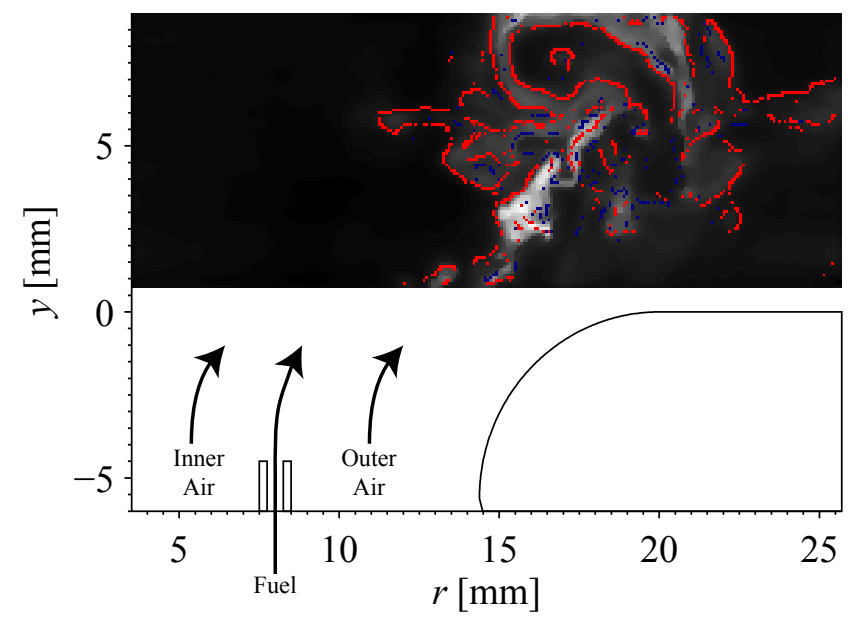

(b) Acetone PLIF image overlapped with $\xi$.

Fig. 8. Simultaneous fully processed (a) $\mathrm{NO}_{2}$ and (b) acetone PLIF images with overlapped instantaneous flame index, $\xi$, previously shown in Figs. 5 and 6, from case P-3. 


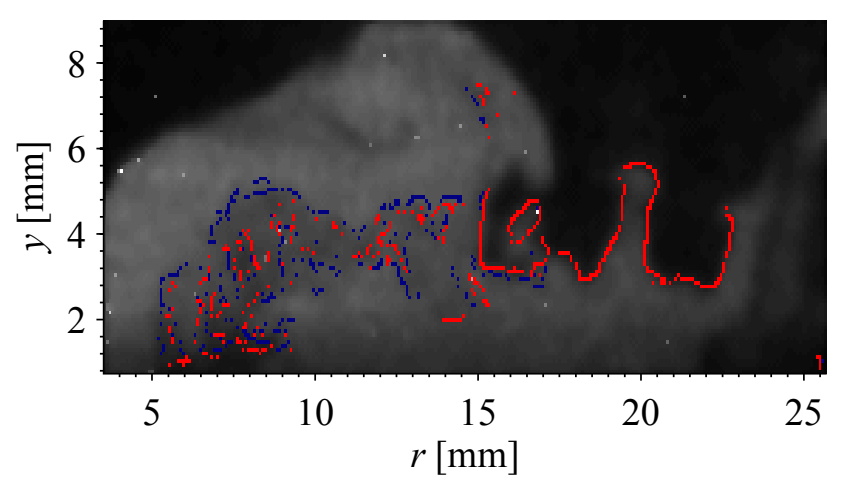

(a) $\mathrm{NO}_{2}$ PLIF image overlapped with $\xi$.

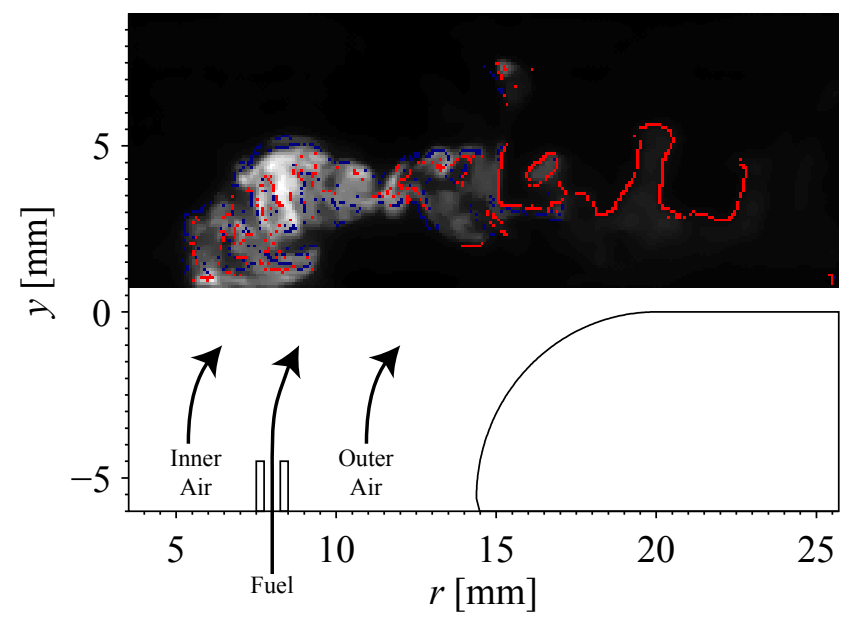

(b) Acetone PLIF image overlapped with $\xi$.

Fig. 9. Simultaneous fully processed (a) $\mathrm{NO}_{2}$ and (b) acetone PLIF images with overlapped instantaneous $\xi$, previously shown in Fig. 6b, from case P-3. 


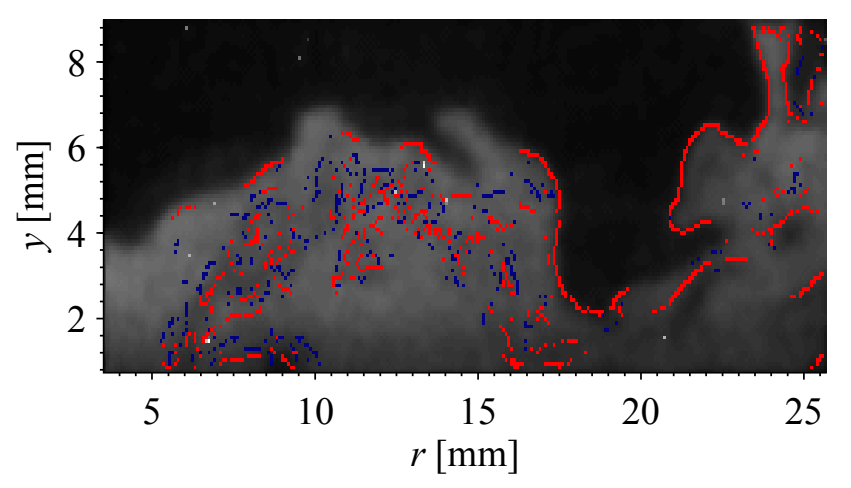

(a) $\mathrm{NO}_{2}$ PLIF image overlapped with $\xi$.

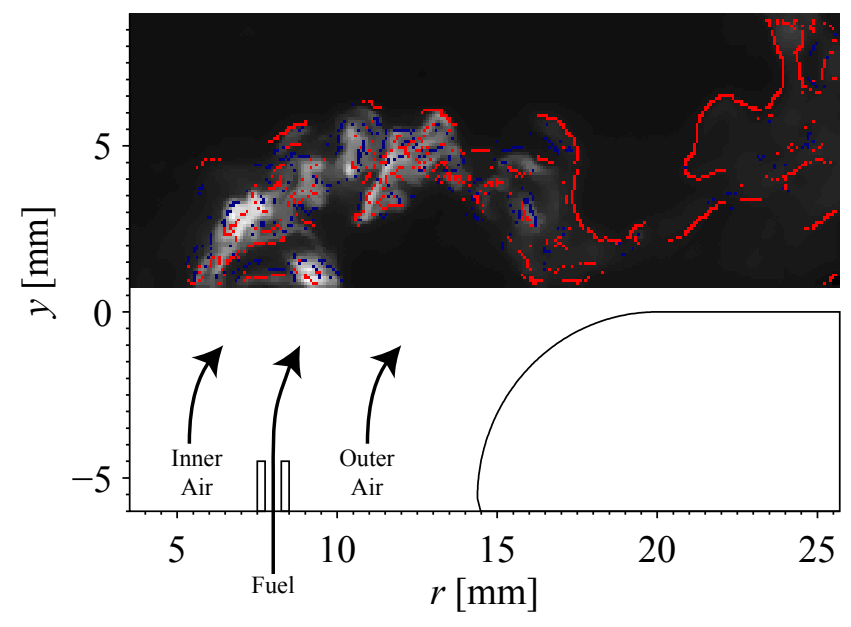

(b) Acetone PLIF image overlapped with $\xi$.

Fig. 10. Simultaneous fully processed (a) $\mathrm{NO}_{2}$ and (b) acetone PLIF images with overlapped instantaneous $\xi$, previously shown in Fig. 7b, from case P-3. 


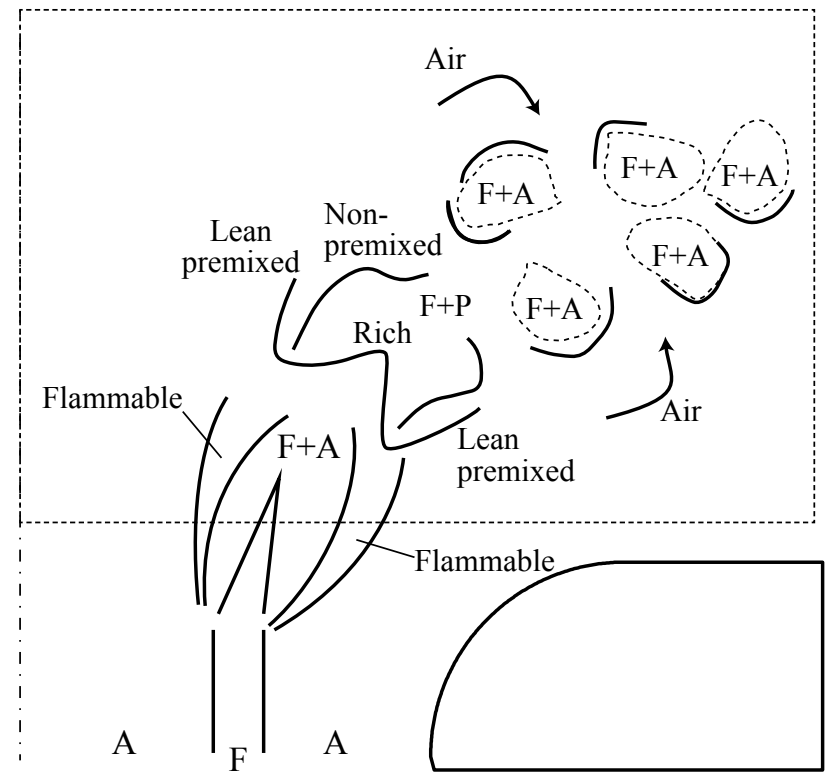

Fig. 11. Schematic showing non-premixed conditions above the fuel port and premixed conditions downstream, which can explain the data in Figs. 6 and 7.

premixed flamelets always lie at the edge of the acetone (fuel) boundary; they are never embedded within the fuel.

At a different instant in time, the flame index pattern is shown in Fig. 6b. This flame index pattern is overlapped with the $\mathrm{NO}_{2}$ and acetone signals in Figs. 9a and 9b. Also it is seen the fuel in Fig. 9b is confined to a much narrower region than the $\mathrm{O}_{2}$ region in Fig. 9a. This is believed to indicate that the fuel is less well-mixed at the time corresponding to Fig. 9 than at the previous time (Fig. 8). Not surprisingly, there are more non-premixed flamelets at this second instant in time (in Fig. 6b) than at the first instant (Fig. 6a), because the fuel is concentrated to a smaller region in space at the second instant. At a third instant in time, Figs. 7a, 10a, and 10b display the same trends as were seen in the previous images.

It is seen that above the fuel port the combustion is more likely to be non-premixed. Farther downstream the combustion has a higher probability of being premixed. Near the fuel port the air surrounds regions of pure fuel, so non-premixed conditions are more likely. At downstream locations the swirling air has had time to mix with the fuel, so premixed conditions are likely. Downstream locations are in the upper right corner since the swirl causes the streamlines to move radially outward. One encouraging observation is that the diagnostics yield flamelets that are continuous and confined to relatively long, thin layers. The value of $\xi$ assigned to each pixel is determined independently using Eq. (1) from the local gradients. So if significant errors were occurring, it is unlikely that the pixels would be properly correlated to create the continuous and long layers that are seen.

Figures 6 and 7 are consistent with the chemiluminescence image in Fig. 4 that shows the flame brush to be horizontal and flat, with a thickness of about $10 \mathrm{~mm}$. As expected Figs. 6 and 7 also show that the flame brush has a hole in the middle because pure air is injected on the centerline and the swirl directs all fluids radially outward. The flame brush in Fig. 4 is flat for the same reasons that a counterflow laminar flame is flat. In the GTMC experiment the swirl in the inner and outer air streams create a radially-outward gas velocity that causes the streamlines to diverge, much like the streamlines in a counterflow flame.

Recognizable structures are visible in the images in Figs. 6 and 7, so Fig. 11 is presented as our explanation. Just above the annular fuel port there is expected to be a jet core that is surrounded by inner and outer shear layers. The shear layers tend to create the flammable regions that are drawn in Fig. 11. Just above the fuel port the mixture is too fuel-rich to be flammable, while far from the fuel port the mixture is too-fuel lean to be flammable. The lifted base is believed to have a structure similar to a triple flame in that rich premixed flames are likely to occur just above the fuel port. The swirl forces air into the mixing region and creates premixed pockets 
downstream. The suggested structure in Fig. 11 can explain why non-premixed flamelets are more probable above the fuel jet, while premixed flamelets are more likely to be seen downstream.

The physical picture observed in the previous figures is consistent with different types of measurements reported by Wiegand et al. [50] and Stöhr et al. [26]. They did not measure flame index but they used Raman, $\mathrm{CH}$, and $\mathrm{OH}$ fluorescence diagnostics to record the local fuel-air ratio and flame structure in a nearly-identical GTMC burner. Wiegand et al. found that "The near field of the flames was characterized by fast mixing" and that "strongly corrugated reaction zones are cut and ... interrupted." Their $\mathrm{CH}$ and $\mathrm{OH}$ images show shredded reaction layers that have shapes that are similar to Fig. 6 but they could not determine which flamelets are premixed and which are non-premixed. They do show that large vortex-like structures occur, as are seen in Fig. 5 above. Stöhr et al. [26] explain that one source of vortex-like structures is the precessing vortex core that rapidly mixes the fuel and air and thus promotes premixed combustion. They also used an acetone tracer to obtain a qualitative understanding of where the fuel mixes. They do not determine the fraction of flamelets that are premixed, but our values of $74 \%$ to $79 \%$ are consistent with their qualitative findings.

\subsection{General features compared to DNS and LES}

It is desired to compare the measured flame index structure seen in Figs. 6 and 7 to relevant DNS and LES computations, but unfortunately there are no published DNS results for Reynolds numbers in the range of the present experiment. Furthermore, there are only a few LES computations of flame index because appropriate subgrid models of partially-premixed combustion are still under

development. For lifted jet geometries that are very different from the present experiment, some computed values of flame index were reported in Refs. [1-3, 8, 16, 52, 53].

For swirl-flames, the authors are aware of only two computations that report flame index, and in both cases only spray flames were considered. They are the DNS study of Luo et al. [9] and the LES study of Patel and Menon [17]. For these two studies the computed flame index is shown in Fig. 12. In both examples the fuel is injected through an annular ring that is surrounded by both inner and outer swirling air, as in our experiment. In Fig. 12a the fuel layers, the premixed flames, and the non-premixed flames are marked. In Fig. 12b the greyscale indicates the product of two quantities; the flame index and the reaction rate. The black region in Fig. 12b is where premixed combustion is predicted while the white region represents non-premixed combustion.

It is impossible to make any quantitative comparisons between Fig. 12 and the present measurements because of the many differences between the operating conditions. However it is interesting to note some general features that are similar. One is the location of the premixed and non-premixed flamelets. In Fig. 12 and in Fig. 6 there are many premixed flamelets that occur in the downstream region of the swirl flames. Apparently the strong coaxial, swirled air causes significant premixing of fuel and air to occur in the downstream region. Another similarity is that the computations in Ref. [9] predict that premixed combustion contributes $70 \%$ of their total heat release rate. Inspection of our images in Figs. 6 and 7 qualitatively indicates that well over half of our measured flamelets are premixed. In the next section it is determined that between $70 \%$ and $80 \%$ of our flamelets are premixed. A more quantitative comparison is not possible because the heat release of the measured flamelets is not known. Another feature that is similar in Figs. 6 and $12 \mathrm{~b}$ is that the flamelets are discontinuous (shredded) and highly wrinkled. However, the lower Reynolds number simulation in Fig. 12a contains only continuous reaction layers.

\subsection{Fraction of all flamelets that are premixed $(\beta)$}

A useful metric that can be used to compare experiments and simulations is the global fraction of all flamelets that are premixed, $\beta$. $\beta$ was measured by first determining the probability density function, $\operatorname{Pr}(\xi)$, from an ensemble of values collected at all locations in all of the images. The PDF has three spikes and under each spike is the area $A, B$, or $C$, as is represented by Eq. (3). $\beta$ is defined by Eq. (2) to be the spatially-averaged value of $C /(A+C)$. 


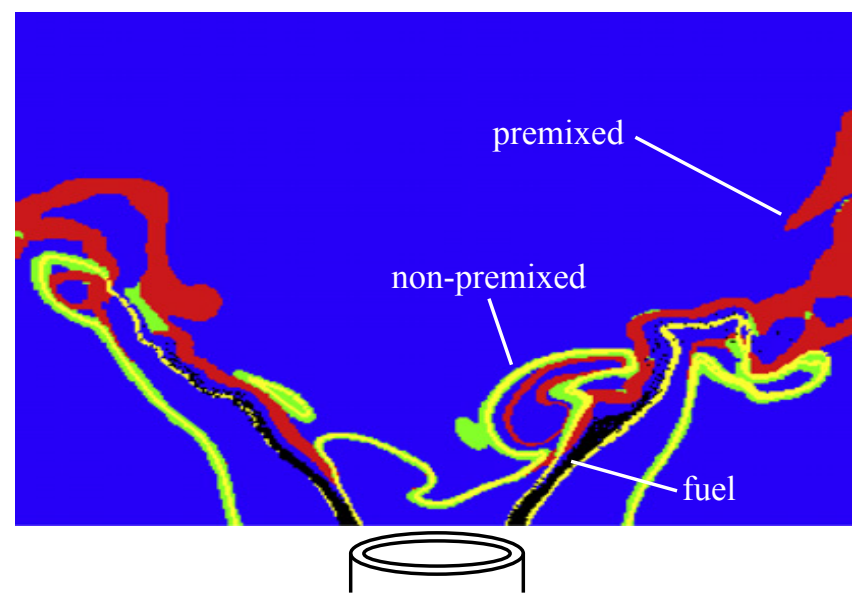

(a)

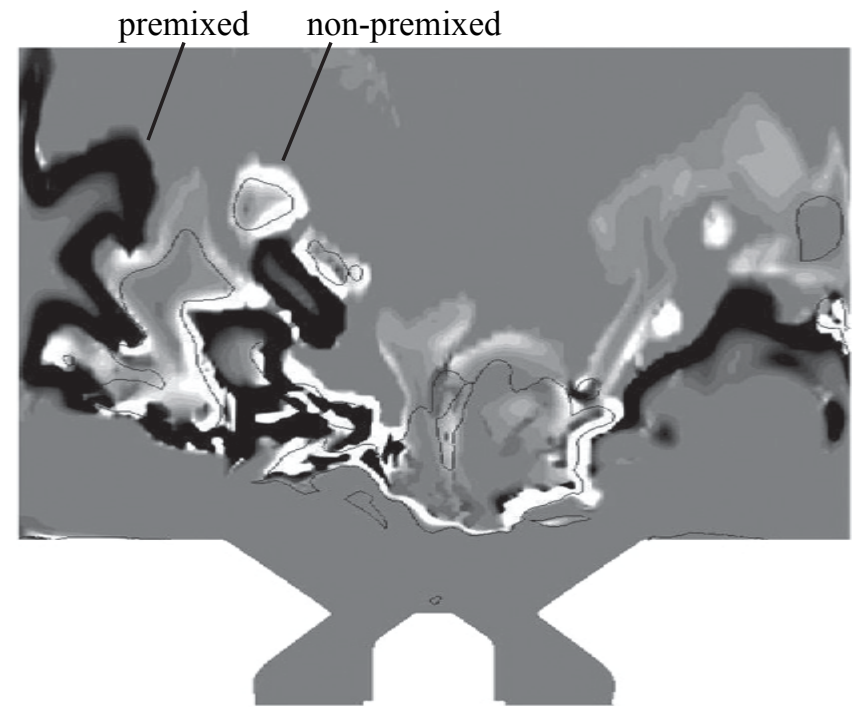

(b)

Fig. 12. Flame index computed in swirl spray flames. (a) DNS of Luo et al. [9]; (b) LES of the product of flame index and reaction rate by Patel and Menon [17]. 
Values of $\beta$ are listed in Table 2. For case P-1 about $80 \%$ of the flamelets were premixed even though the fuel and air were initially non-premixed because the fuel was injected in a separate annular stream. When the fuel is injected separately from the air, it is common to apply a model that assumes that all of the combustion will be non-premixed. However this is not appropriate when the flame base becomes lifted. Table 2 also indicates that the fraction of flamelets that were premixed $(\beta)$ increased from 0.74 to 0.80 as the velocity ratio was increased by $55 \%$. A larger fuel injection velocity was observed to cause the fuel jet to become longer, so more of the fuel jet exists at downstream locations where more intense premixing occurs. This is one explanation of the measured trend. Other parameters that also are believed to control $\beta$ are the swirl number and the burner geometry, but varying these two parameters was not within the scope of the present work. Initially it was expected that the overall fuel-air ratio would control the fraction of flamelets that were premixed. That is, it was expected that larger equivalence ratio would lead to more non-premixed and fewer premixed flamelets. However, this was not found to be the case.

Another quantity of interest is the flame index averaged over all values of flame index that are nonzero, which means that it only considers locations where a flamelet exists. This conditionally averaged flame index is defined to be:

$$
\langle\xi \mid \xi \neq 0\rangle=\frac{C-A}{A+C}
$$

The contours of conditionally averaged flame index appear in the thesis [46] and are not plotted here because they are nearly identical in shape to the contours of $\beta$ that appear in Fig. 13.

Another statistical quantity of interest is the degree of partial-premixing, $\epsilon$, which we define to be:

$$
\epsilon=\frac{\beta(1-\beta)}{0.25}
$$

The quantity $\epsilon$ is useful to determine whether or not partially-premixed combustion occurs. It has a maximum value of unity when half of the flamelets are premixed $(\beta=0.5)$ and half are non-premixed. It has a value of zero if all flamelets are premixed or if all flamelets are non-premixed. Measured values of $\epsilon$ were $0.65,0.69$, and 0.77 for cases P-1, P-2 and P-3, indicating that the GTMC burner provides a good example of partially-premixed combustion.

\subsection{Spatial variation of the fraction of flamelets that are premixed}

A useful assessment of an LES submodel is its ability to correctly predict the spatial variation of the fraction of flamelets that are premixed. Figure 13 displays contours of this quantity, which is $[C /(A+C)] ; A$ and $C$ are the components of the PDF given by Eq. (3). It is seen that just above the fuel jet only $50 \%$ of the flamelets are premixed, but this increases to $90 \%$ downstream. Non-premixed flamelets are likely to surround the fuel-rich jet that issues from the annular fuel port, while premixed flamelets are more probable downstream where more air has been entrained.

Figure 13 is consistent with the values of $\beta$ in Table 2. For case $\mathrm{P}-1$ the value of $\beta$ indicates that $80 \%$ of all flamelets are premixed. Figure 13a shows that at downstream locations (in the upper right) the contour exists that marks where $90 \%$ of flamelets are premixed. At the location above the fuel jet lies the contour where $65 \%$ of flamelets are premixed and where $35 \%$ are non-premixed. A possible explanation is offered by Fig. 11; regions of unmixed fuel issue from the jet and can be surrounded by non-premixed flames. Apparently, downstream there are relatively few regions of unmixed fuel. Comparing Figs. 13b and 13c to Fig. 13a, it is seen that there is some change in the locations of the contours, but the total fraction of premixed flamelets only changes by a modest amount.

The mean flame index, $\bar{\xi}$, is plotted in Fig. 14; it is defined to be the integral of $\xi \operatorname{Pr}(\xi) \mathrm{d} \xi$, that is integrated over all values of $\xi$. Thus $\bar{\xi}$ is equal to $(C-A)$, where $C$ and $A$ are defined by Eq. (3). It is noted that the values of $\bar{\xi}$ on the contours are small and range from 0.005 to 0.035 . Where this mean value is 0.035 the flamelets are nearly all premixed $(\xi=+1)$ but flamelets are present only about $3.5 \%$ of the time. At other locations $\bar{\xi}$ is nearly zero; this indicates that either $50 \%$ of flamelets are premixed or there may be no flamelets present. Figure 14 is consistent with Fig. 13 in that the values of $\bar{\xi}$ above the fuel injector are smaller than the values downstream. At the 


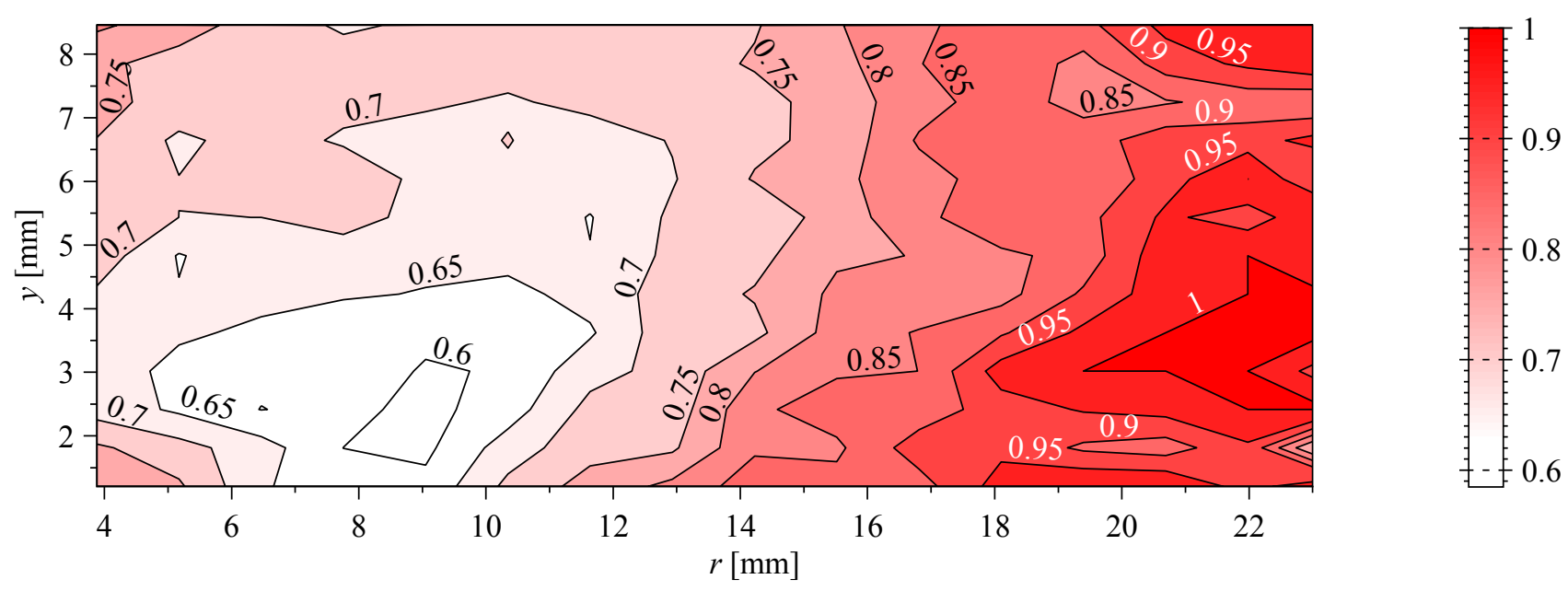

(a) Case P-1, fuel-rich equivalence ratio, high velocity ratio, and low flow rate.

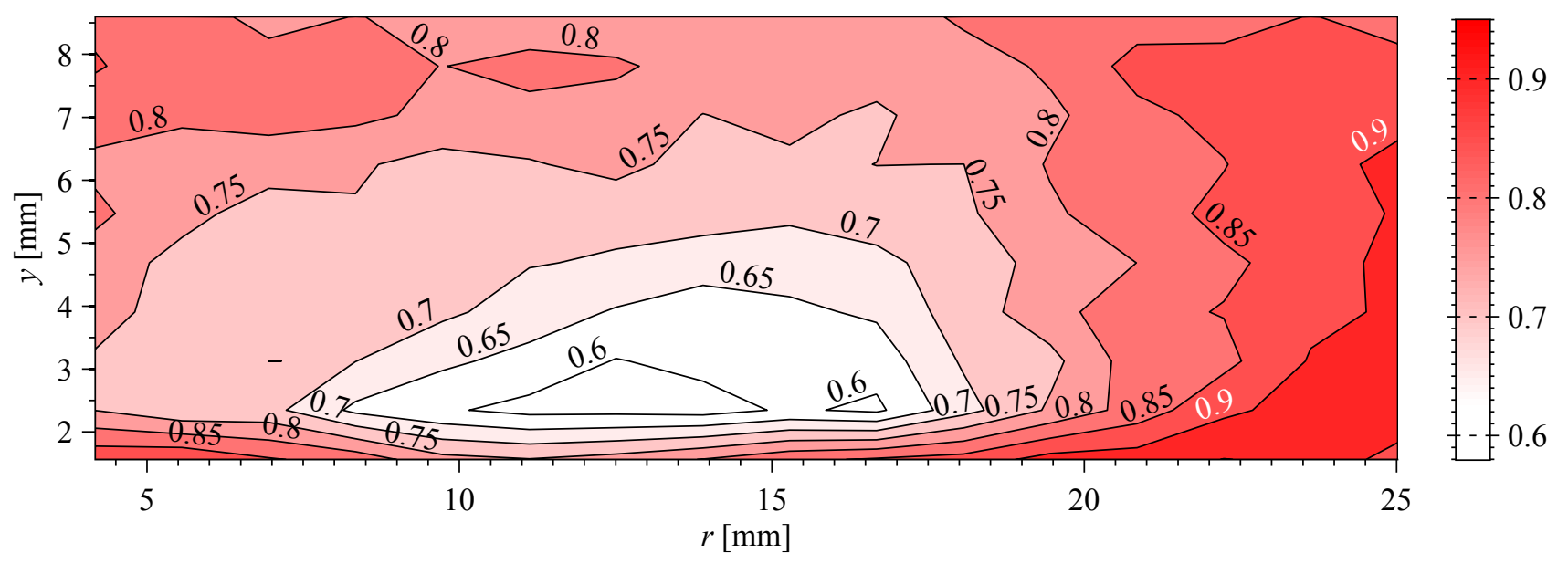

(b) Case P-2, fuel-rich equivalence ratio, high velocity ratio, and high flow rate.

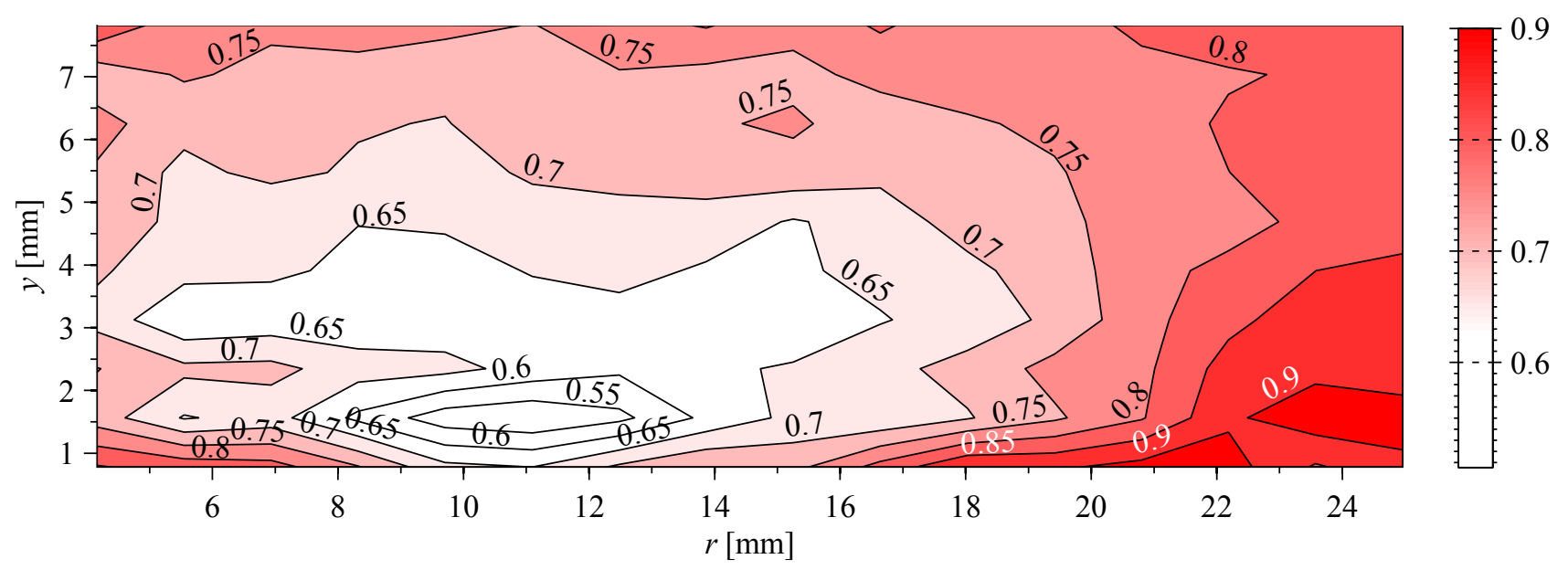

(c) Case P-3, fuel-lean equivalence ratio, low velocity ratio, and high flow rate.

Fig. 13. Fraction of flamelets that are premixed, which equals $C /(A+C)$. 


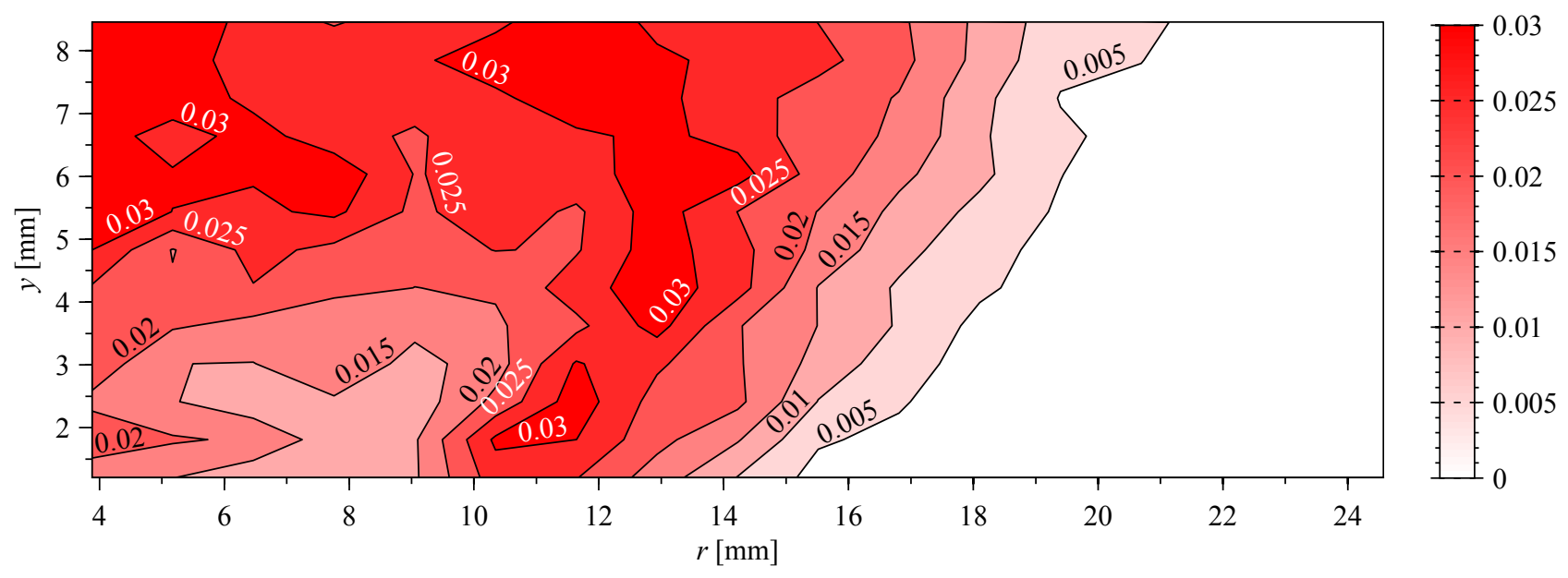

(a) Case P-1, fuel-rich equivalence ratio, high velocity ratio, and low flow rate.

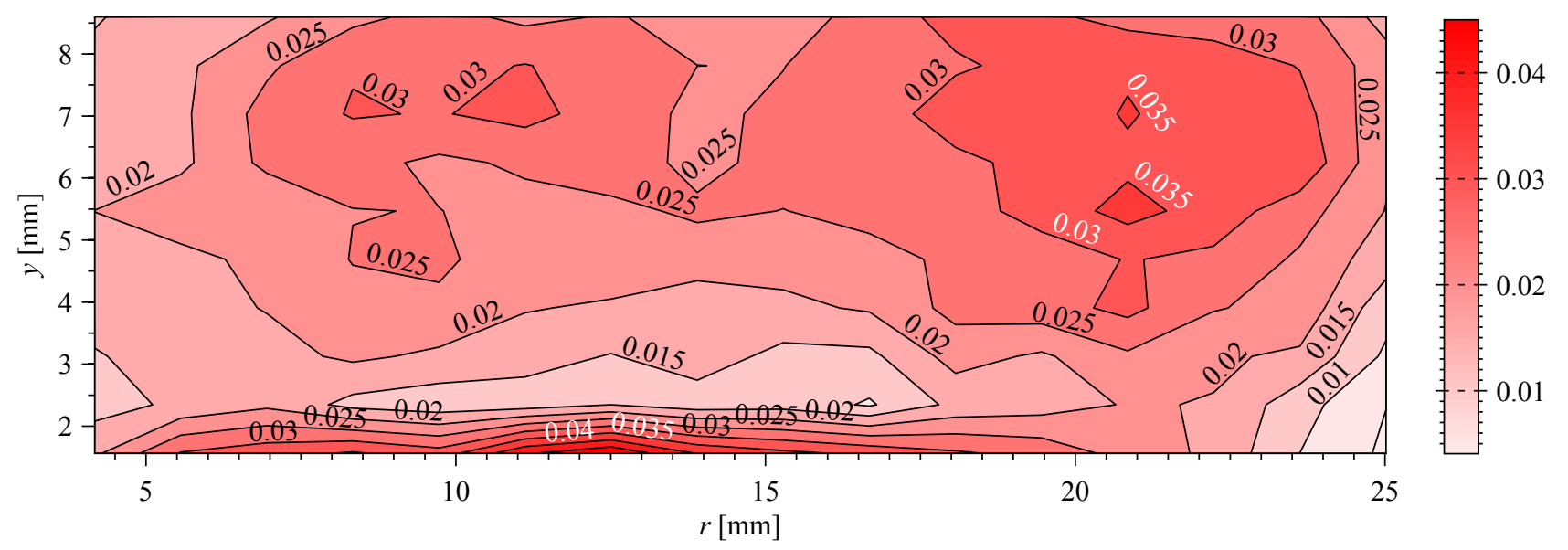

(b) Case P-2, fuel-rich equivalence ratio, high velocity ratio, and high flow rate.

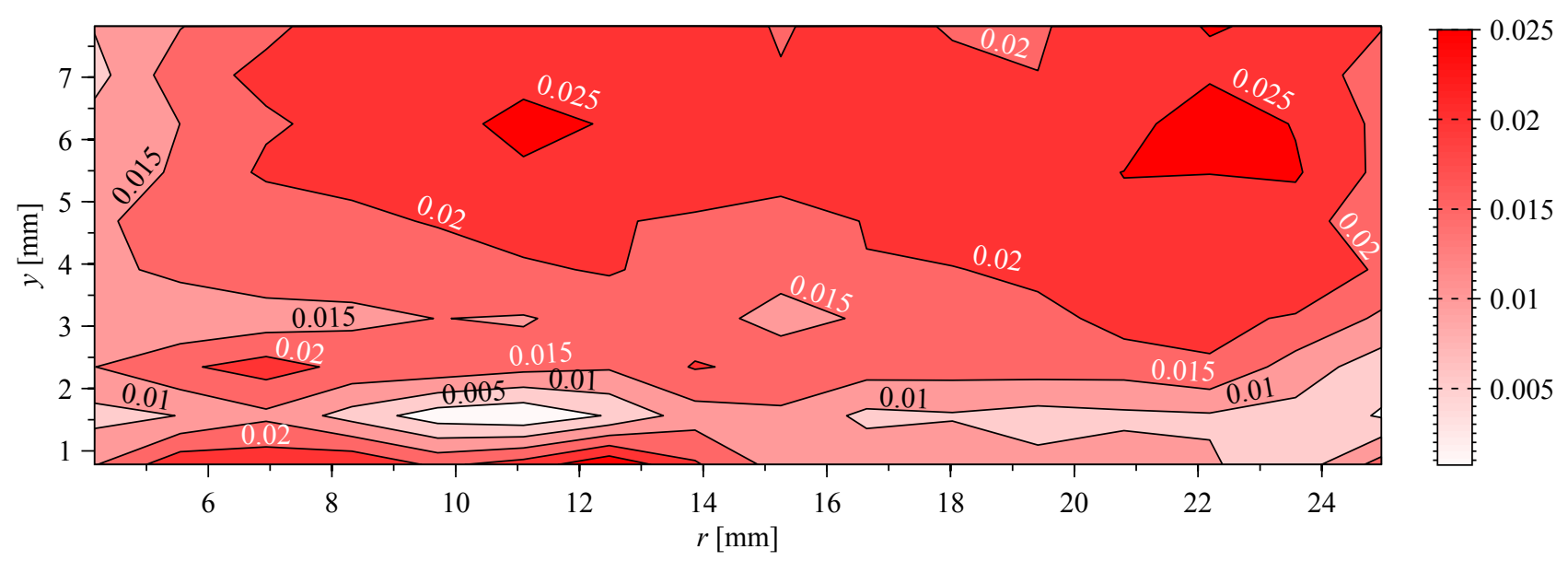

(c) Case P-3, fuel-lean equivalence ratio, low velocity ratio, and high flow rate.

Fig. 14. Contours of mean flame index, $\bar{\xi}$, which equals $(C-A)$. 
upper edge of Figs. 14b and 14c the values of $\bar{\xi}$ appear to be decreasing, which is believed to be due to the disappearance of flamelets as the recirculation zone is approached. This observation is consistent with the fact that the chemiluminescence in Fig. 4 is confined to a relatively flat and horizontal region that does not extend upward very far above the field of view of Figs. 13 and 14. It is believed that this decrease in $\bar{\xi}$ is not observed in Fig. 14a, because the reduced flow rate has drastically changed the flow structure of the flame.

\section{Summary comments}

A new method has been developed to measure the flame index, $\xi$ in partially-premixed turbulent combustion. Values of the mean and instantaneous flame index were recorded in the Gas Turbine Model Combustor designed by Meier at DLR. Acetone was selected to be one component of the fuel and $\mathrm{NO}_{2}$ was added to the air.

To assess the new method, calibration experiments and CHEMKIN computations were performed. Results demonstrate that the directions of the gradients of the acetone and $\mathrm{NO}_{2}$ PLIF signals are accurate indicators of the directions of the gradients of the fuel and $\mathrm{O}_{2}$, respectively. Two criteria were determined to provide a satisfactory way to differentiate between flamelets and non-reacting mixing layers. First, chemical reactions cause the gradients in flamelets to exceed a threshold magnitude. Secondly, there is a specific structure to the fuel and $\mathrm{O}_{2}$ gradients in a reaction layer that differs from the structure of a mixing layer. A gap occurs between the profiles of fuel and $\mathrm{O}_{2}$ within non-premixed flames but this gap does not occur in non-reacting mixing layers. Algorithms were written to apply these two criteria to the data set. The calibration study also optimized the signal-to-noise level in order to achieve values of 24 for the acetone and 13 for the $\mathrm{NO}_{2}$ PLIF signal.

\section{Conclusion}

The fraction of flamelets that are premixed displayed large differences in two regions. Just above the annular fuel injector there is a high probability of non-premixed flamelets, but farther downstream most of the flamelets are premixed. This trend differs from that of a lifted jet flame. DNS of a lifted jet had shown that premixed flamelets are confined to the flame base, much like a triple flame. In contrast, the swirl burner provides intense mixing downstream where the flamelets are primarily premixed.

The global fraction of flamelets that are premixed, $\beta$, was measured to be $74 \%$ for case P-1. This value is in the range of previous DNS computations [9] although the computations were at different conditions and at much lower Reynolds numbers than the experiment. This finding has implications for modeling; even though the fuel and the air are injected separately, the mixing is so intense and the flame base is lifted, so a model that is predominantly based on non-premixed concepts is not appropriate.

One important governing parameter in partially-premixed combustion was found to be the ratio of injection velocity of the fuel to the air velocity. As this ratio increased the fraction of flamelets that are premixed also increased. A possible explanation is that larger fuel injection velocities increase the fuel jet penetration distance, so more of the fuel enters the intense mixing region downstream, which leads to more premixed combustion. The overall fuel-air equivalence ratio did not seem to be a governing parameter, since overall richer conditions did not produce more non-premixed flamelets.

After a detailed uncertainty analysis was conducted along with calibration experiments, it was determined that there are two nontrivial source of uncertainty in measuring flame index. Approximately $6 \%$ of the flamelets that are known to exist (in a laminar calibration experiment) were not recorded where the signal-to-noise ratio is lower than average. About a $10 \%$ error is due to the method used to differentiate between non-premixed flamelets and non-reacting shear layers. The former has a gap between fuel and air profiles but the latter does not. The magnitudes of the signal gradients are used only to determine where gradients exceed a certain threshold value. Magnitudes of species mass fractions are not used to determine flame index because they appear in both the numerator and denominator of its definition, Eq. (1). The overall uncertainty is estimated to be $12 \%$ and it is not believed to be large enough to affect the conclusions. 


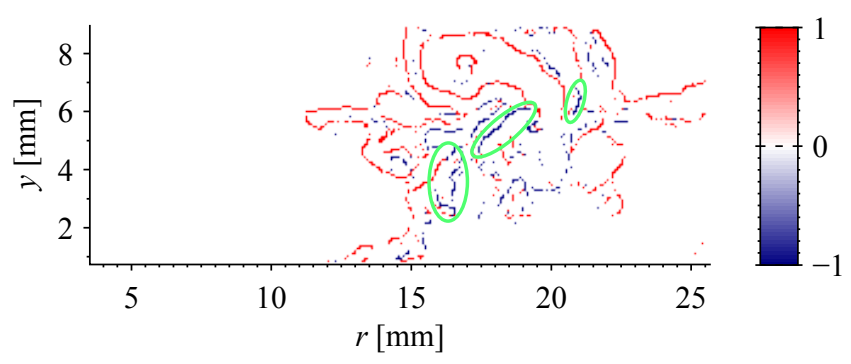

Fig. B.15. Instantaneous flame index that was shown in Fig. 6a from case P-3, but without the $0.13 \mathrm{~mm}$ minimum gradient separation imposed. Non-reacting mixing layers are circled. The burner centerline is located at $r=0 \mathrm{~mm}$, while the burner exit plane is located at a height of $y=0 \mathrm{~mm}$. The field of view is $8 \mathrm{~mm}$ by $23 \mathrm{~mm}$.

\section{Acknowledgments}

Funding for this research was provided by the National Science Foundation award CBET 0852910, which was monitored by Dr. Arvind Atreya and Dr. Ruey-Hung Chen. Some equipment also was funded by the Office of Naval Research under grant N00014-1010561 and by the DOEUTSR program under grant FE0007060. We thank Dr. Wolfgang Meier of DLR Stuttgart for permission to use his GTMC design.

\section{Appendix A. Calibration of the $\mathrm{NO}_{2}$ diagnostics}

For non-reacting conditions, a calibration study was conducted in a chamber to insure that the $\mathrm{NO}_{2}$ PLIF signal is a linear function of the $\mathrm{NO}_{2}$ mole fraction and the laser energy. First the mole fraction of $\mathrm{NO}_{2}$ was increased to $5000 \mathrm{ppm}$ within a chamber that contained air at $1 \mathrm{~atm}, 296 \mathrm{~K}$. A linear relation was measured between the fluorescence signal and $\mathrm{NO}_{2}$ mole fraction. Gulati and Warren [40] also reported a linear trend, but their conditions differed from ours in that they used a much lower $\mathrm{NO}_{2}$ mole fractions, different laser wavelength, and lower laser energies. Laser energy also was varied and the $\mathrm{NO}_{2}$ PLIF signal displayed a linear trend for energies up to $45 \mathrm{~mJ} /$ pulse [46]. At larger energies the calibration curve started to bend and become non-linear due to saturation effects, so all measurements were made in the linear regime at a laser energy of $45 \mathrm{~mJ} /$ pulse. For the acetone PLIF signal, similar calibration curves were measured that displayed linear trends, but these results are not presented because many previous papers [29, 34, 35] have published similar results.

\section{Appendix B. Effects of gradient gap criterion}

Section 4.2 described a minimum gap criterion, $g$, that was imposed between the fuel and oxidizer gradients to ensure that no nonreacting mixing layers were incorrectly identified as non-premixed flamelets. This gap size was set to $0.13 \mathrm{~mm}$. Figure B.15 shows the instantaneous flame index for the case that was shown in Fig. 6a, but without the gap criterion imposed. A few non-reacting mixing layers that were removed by the gap criterion are circled. It can be seen that the gap criterion effectively filtered out these mixing layers and kept them from being considered to be flamelets.

\section{References}

[1] H. Yamashita, M. Shimada, T. Takeno, Proc. Combust. Inst. 26 (1996) 27-34.

[2] Y. Mizobuchi, S. Tachibana, J. Shinio, S. Ogawa, T. Takeno, Proc. Combust. Inst. 29 (2002) 2009-2015. 
[3] K. J. Nogenmyr, J. Kiefer, Z. S. Li, X. S. Bai, M. Aldén, Combust. Flame 157 (2010) 915-924.

[4] E. Mastorakos, Prog. Energy Combust. Sci. 35 (2009) 57-97.

[5] P. Domingo, L. Vervisch, J. Réveillon, Combust. Flame 140 (2005) 172-195.

[6] A. R. Masri, Proc. Combust. Inst. 35 (2015) 1115-1136.

[7] S. Meares, A. R. Masri, Combust. Flame 161 (2014) 484-495.

[8] R. W. Grout, A. Gruber, C. S. Yoo, J. H. Chen, Proc. Combust. Inst. 33 (2011) 1629-1637.

[9] K. Luo, H. Pitsch, M. G. Pai, O. Desjardins, Proc. Combust. Inst. 33 (2011) 2143-2152.

[10] J. Cai, R. S. Barlow, A. N. Karpetis, C. Tong, Proc. Combust. Inst. 33 (2011) 1505-1513.

[11] P. N. Kĩoni, K. N. C. Bray, D. A. Greenhalgh, B. Rogg, Combust. Flame 116 (1999) 192-206.

[12] K. M. Lyons, Prog. Energy Combust. Sci. 33 (2007) 211-231.

[13] K. Bray, P. Domingo, L. Vervisch, Combust. Flame 141 (2005) 431-437.

[14] P. Domingo, L. Vervisch, K. Bray, Combust. Theor. Model. 6 (2002) 529-551.

[15] E. Knudsen, H. Pitsch, Combust. Flame 156 (2009) 678-696.

[16] E. Knudsen, H. Pitsch, Combust. Flame 159 (2012) 242-264.

[17] N. Patel, S. Menon, Combust. Flame 153 (2008) 228-257.

[18] C. D. Pierce, P. Moin, J. Fluid Mech. 504 (2004) 73-97.

[19] M. Ihme, Y. C. See, Combust. Flame 157 (2010) 1850-1862.

[20] M. Ihme, H. Pitsch, Combust. Flame 155 (2008) 90-107.

[21] B. Franzelli, E. Riber, L. Y. Gicquel, T. Poinsot, Combust. Flame 159 (2012) 621-637.

[22] L. Y. M. Gicquel, G. Staffelbach, T. Poinsot, Prog. Energy Combust. Sci. 38 (2012) 782-817.

[23] M. Yaldizli, K. Mehravaran, H. Mohammad, F. A. Jaberi, Combust. Flame 154 (2008) 692-714.

[24] D. C. Haworth, Prog. Energy Combust. Sci. 36 (2010) 168-259.

[25] B. Fiorina, O. Gicquel, L. Vervisch, S. Carpentier, N. Darabiha, Combust. Flame 140 (2005) 147-160.

[26] M. Stöhr, C. M. Arndt, W. Meier, Proc. Combust. Inst. 35 (2015) 3327-3335.

[27] W. Meier, X. R. Duan, P. Weigand, Proc. Combust. Inst. 30 (2005) 835-842.

[28] M. C. Thurber, R. K. Hanson, Exp. Fluids 30 (2001) 93-101.

[29] M. C. Thurber, R. K. Hanson, Appl. Phys. B 69 (1999) 229-240.

[30] M. C. Thurber, F. Grisch, B. J. Kirby, M. Votsmeier, R. K. Hanson, Appl. Opt. 37 (1998) 4963-4978. 
[31] C. Schulz, V. Sick, Prog. Energy Combust. Sci. 31 (2005) 75-121.

[32] C. T. Chong, S. Hochgreb, Combust. Flame 158 (2011) 490-500.

[33] R. A. Bryant, J. F. Driscoll, AIAA J. 39 (2001) 1735-1741.

[34] R. A. Bryant, J. M. Donbar, J. F. Driscoll, Exp. Fluids 28 (2000) 471-476.

[35] A. Lozano, B. Yip, R. K. Hanson, Exp. Fluids 13 (1992) 369-376.

[36] R. K. Hanson, J. M. Seitzman, P. H. Paul, Appl. Phys. B 50 (1990) 441-454.

[37] R. J. Cattolica, Proc. Combust. Inst. 21 (1988) 1551-1559.

[38] R. J. Cattolica, Combust. Sci. Technol. 54 (1987) 61-67.

[39] Y. Agarwal, T. Hadeishi, F. Robben, in: 14th AIAA Aerospace Sciences Meeting, AIAA 76-0136, Washington, DC, 1976.

[40] A. Gulati, R. E. Warren, Jr., J. Propul. Power 10 (1994) 54-61.

[41] D. K. Hsu, D. L. Monts, R. N. Zare, Spectral Atlas of Nitrogen Dioxide, 5530 to 6480 Å, Academic Press, New York, 1978.

[42] R. M. Mihalcea, D. S. Baer, R. K. Hanson, Appl. Opt. 35 (1996) 4059-4064.

[43] V. M. Donnelly, D. G. Keil, F. Kaufman, J. Chem. Phys. 71 (1979) 659-673.

[44] D. G. Keil, V. M. Donnelly, F. Kaufman, J. Chem. Phys. 73 (1980) 1514-1520.

[45] G. Herzberg, Electronic Spectra and Electronic Structure of Polyatomic Molecules, volume 3 of Molecular Spectra and Molecular Structure, Van Nostrand, Princeton, NJ, 1966.

[46] D. A. Rosenberg, A Method to Measure Flame Index in Turbulent Partially-Premixed Flames, Ph.D. thesis, University of Michigan, Ann Arbor, MI, 2014.

[47] N. T. Clemens, in: J. P. Hornak (Ed.), Encyclopedia of Imaging Science and Technology, John Wiley \& Sons, Inc., New York, 2002, pp. 390-419.

[48] P. Perona, J. Malik, IEEE Trans. Pattern Anal. Mach. Intell. 12 (1990) 629-639.

[49] J. Canny, IEEE T. Pattern. Anal. PAMI-8 (1986) 679-698.

[50] P. Weigand, W. Meier, X. R. Duan, W. Stricker, M. Aigner, Combust. Flame 144 (2006) 205-224.

[51] W. Meier, X. R. Duan, P. Weigand, Combust. Flame 144 (2006) 225-236.

[52] F. Zhang, R. Yu, X. S. Bai, Int. J. Hydrogen Energy 37 (2012) 17285-17293.

[53] S. Lu, J. Fan, K. Luo, Int. J. Hydrogen Energy 37 (2012) 3528-3539. 


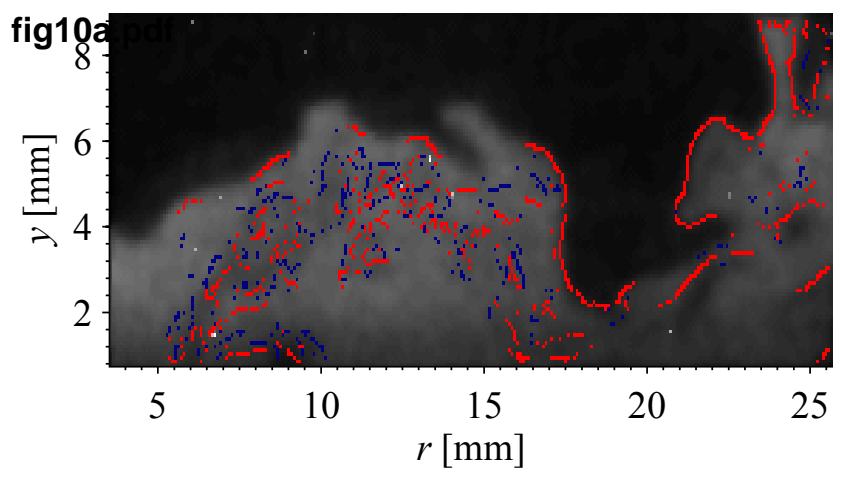




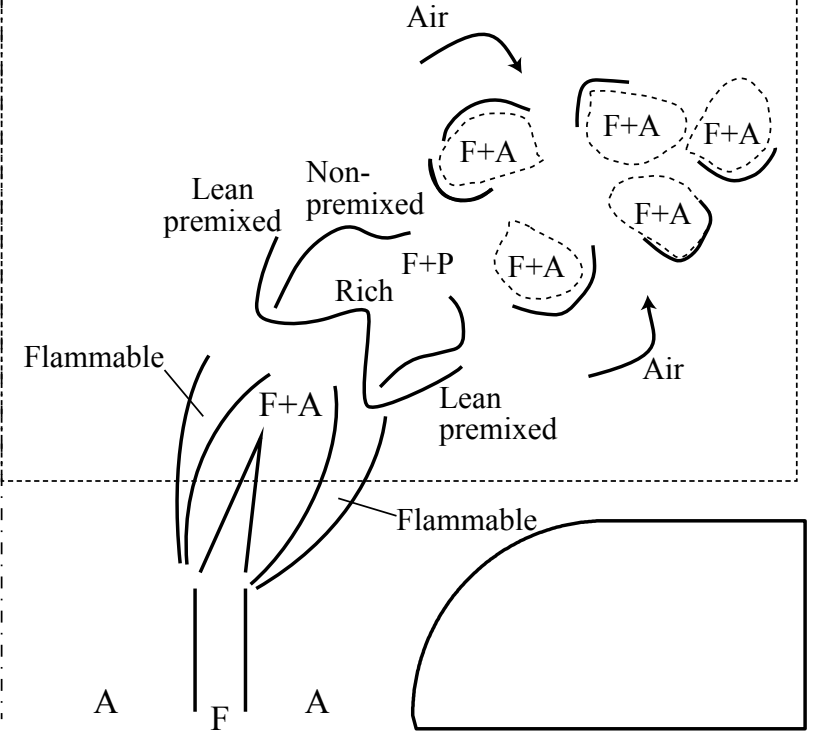


premixed

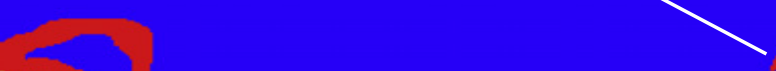

non-premixed
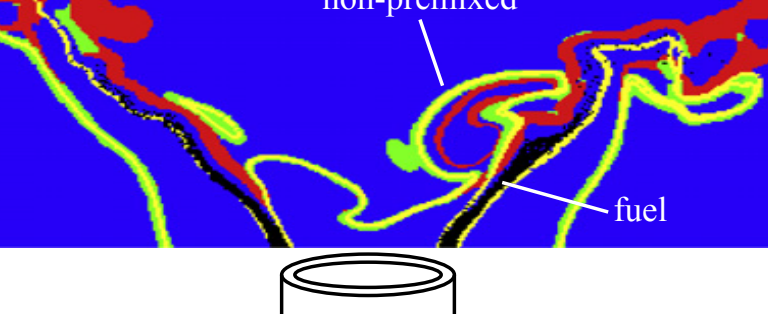
fig12Brpeqfxed non-premixed

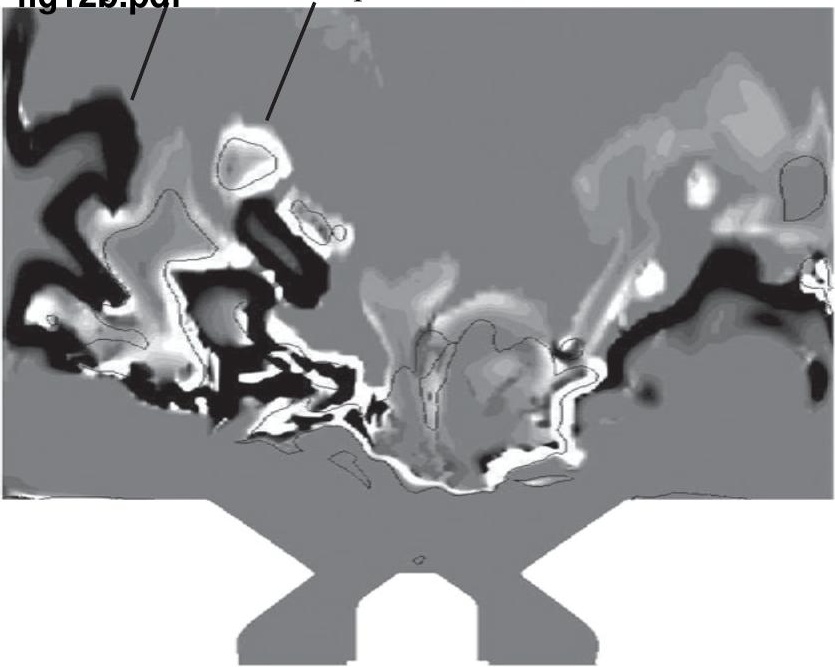




\section{fig13appdf}

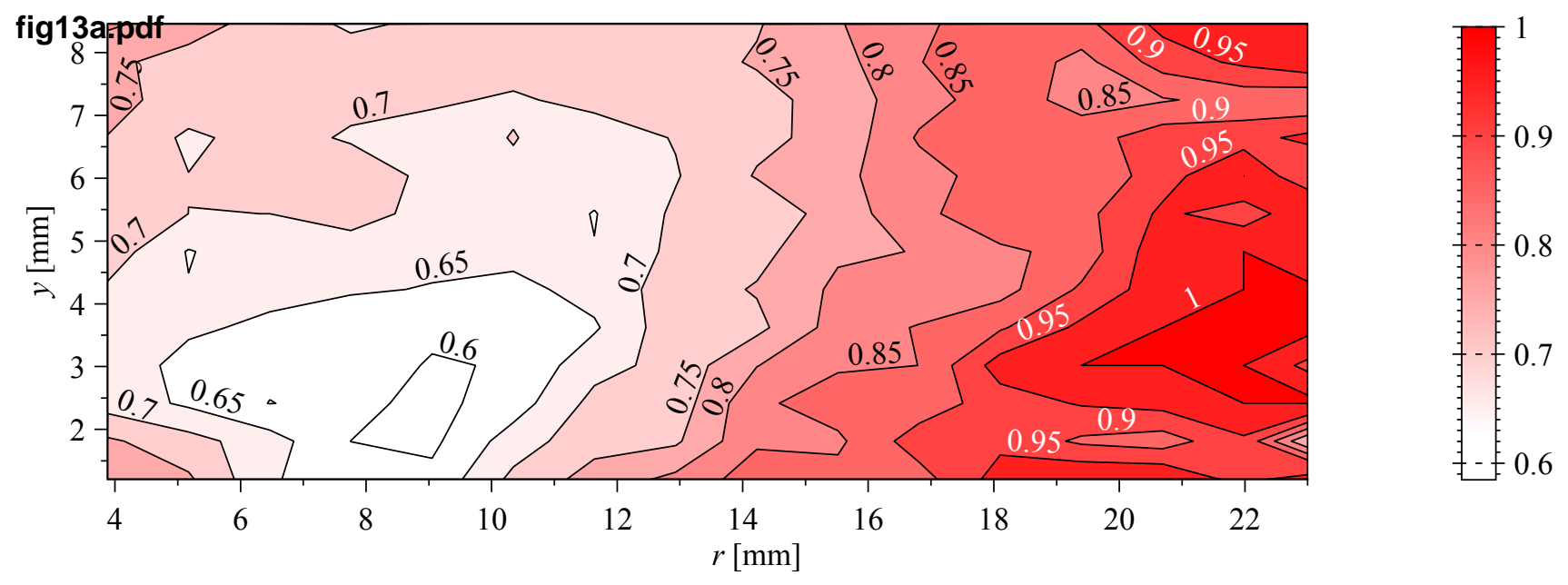




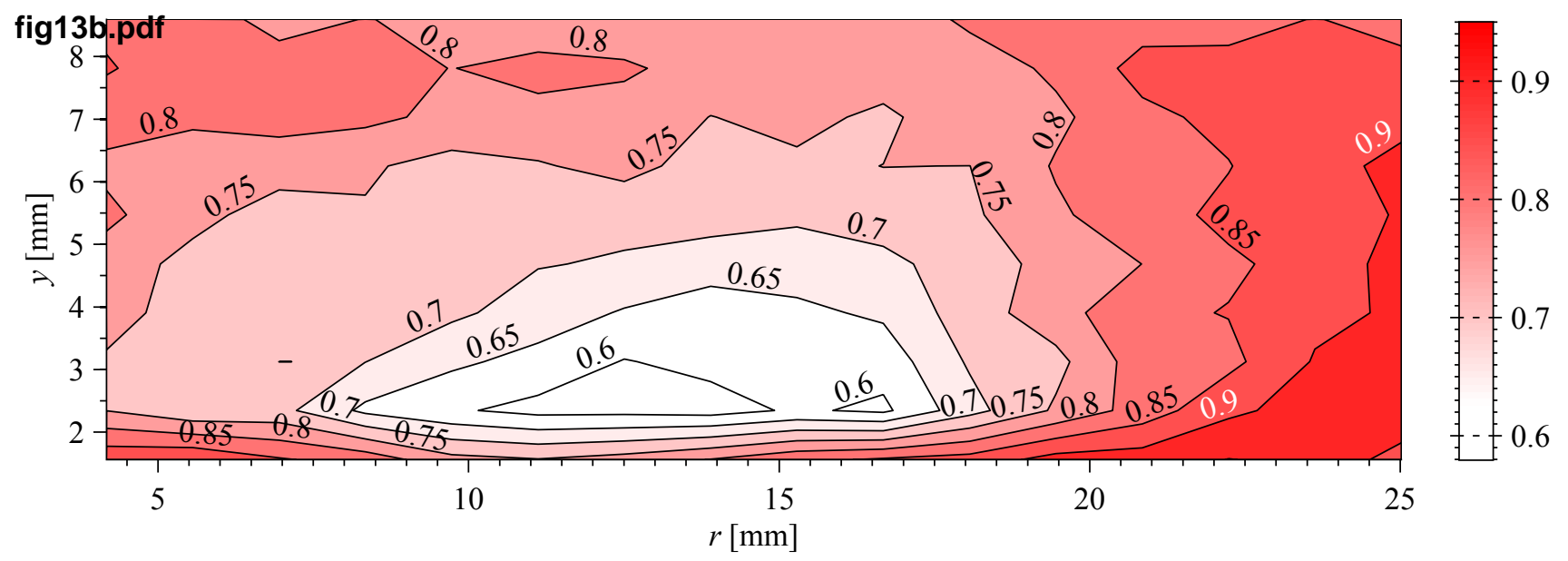


fig13c pelf

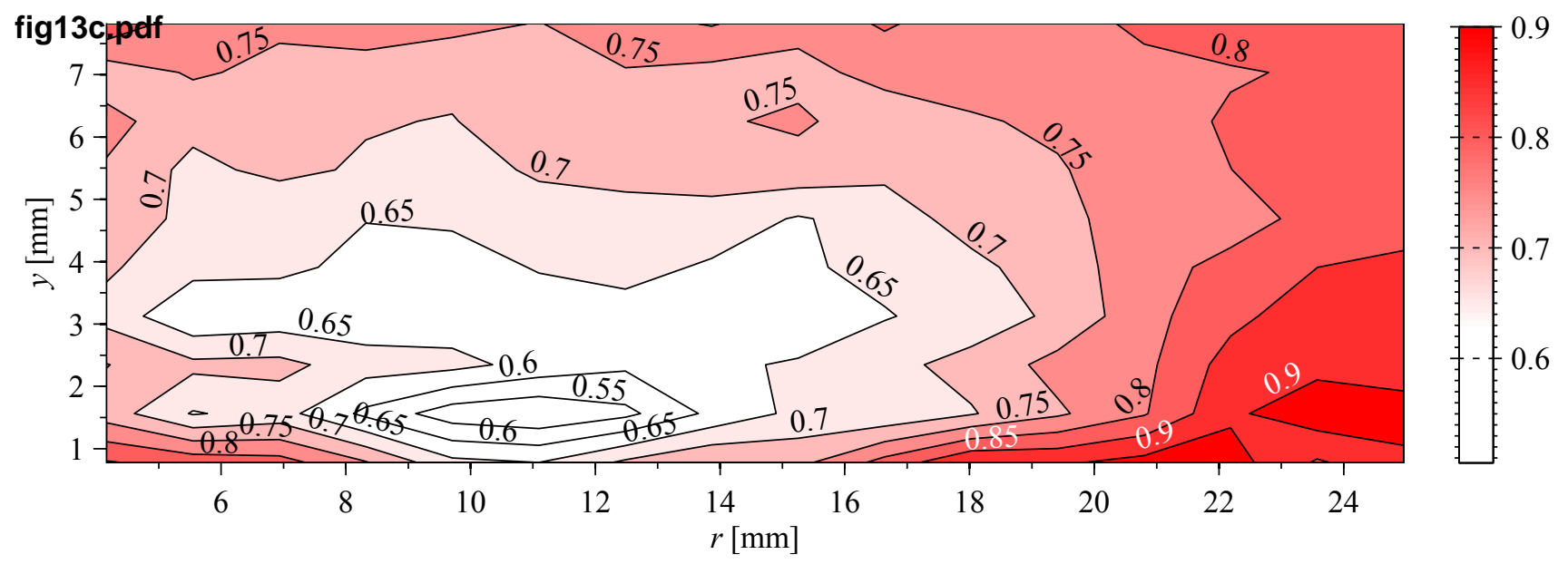


fig14a.pdf

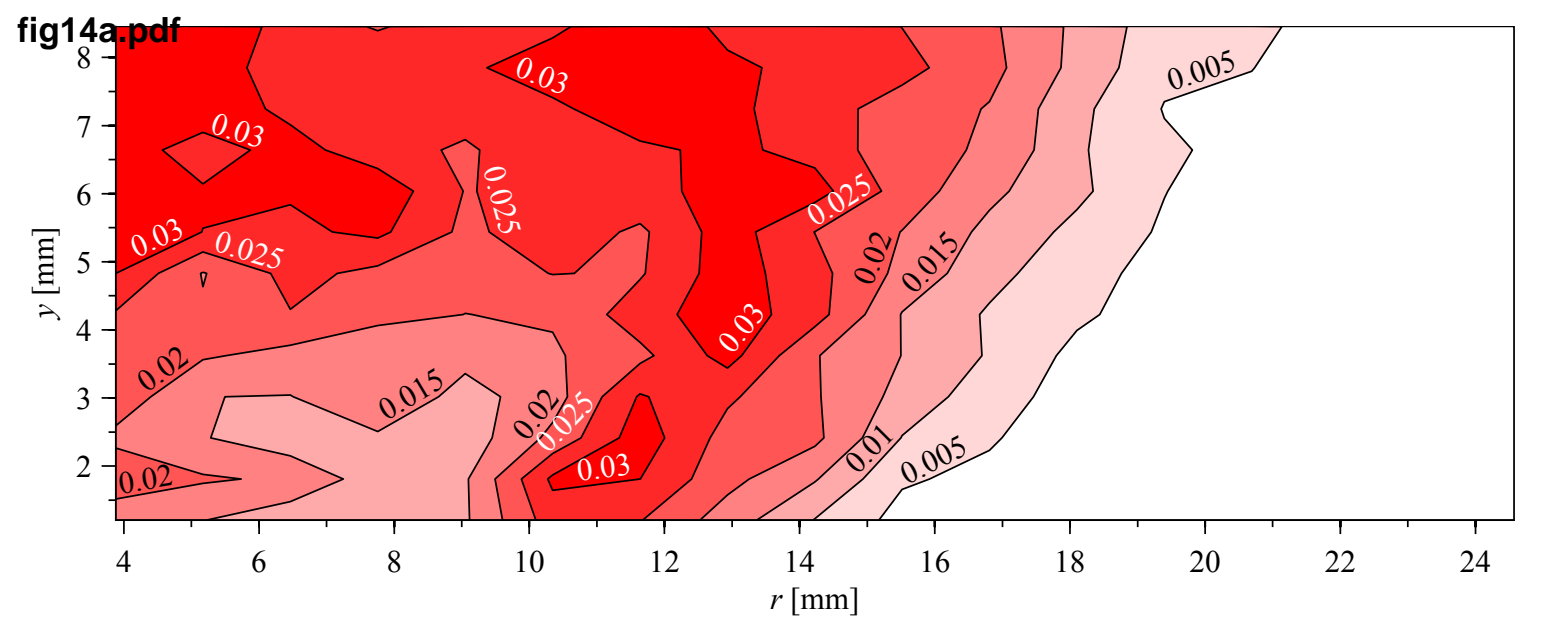


fig14q-pdf

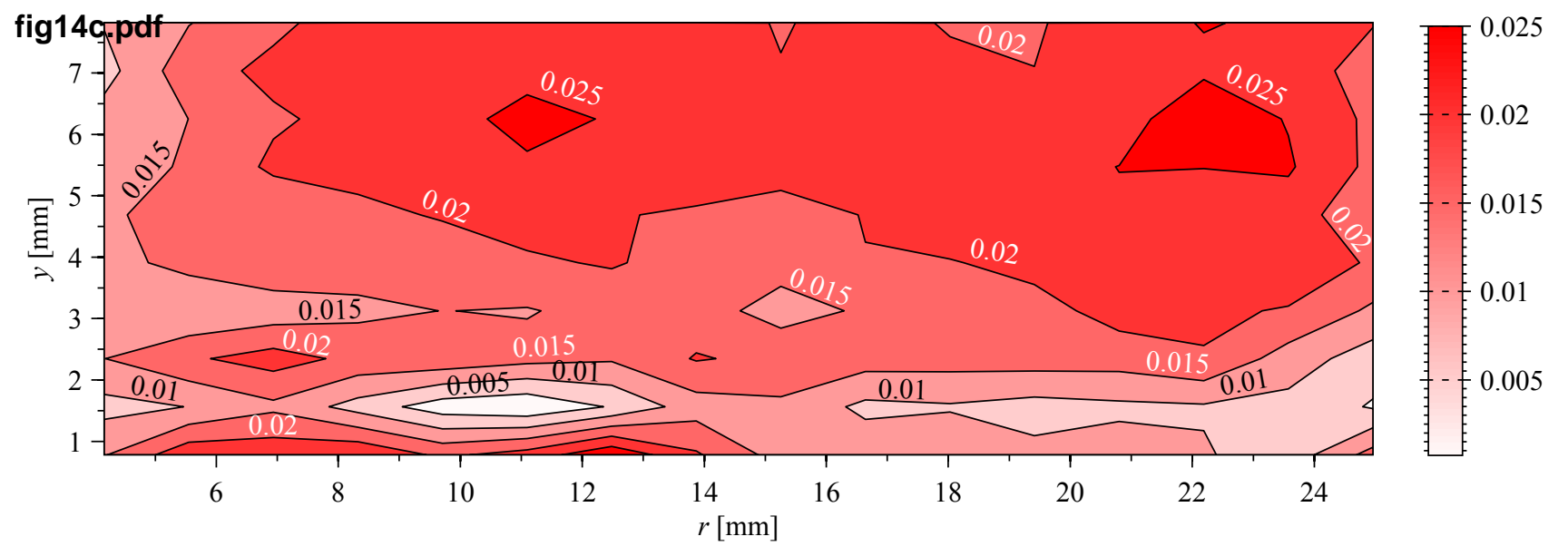




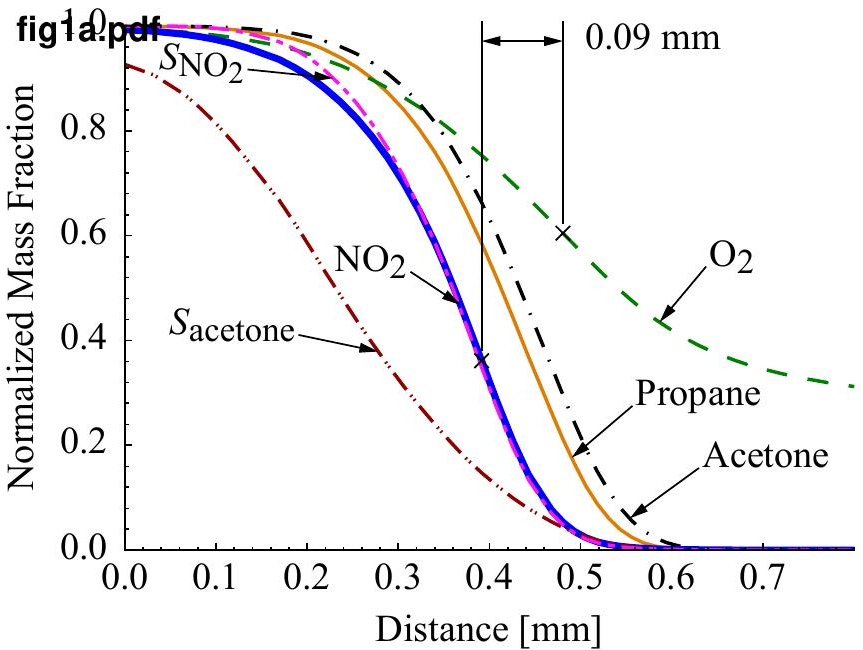




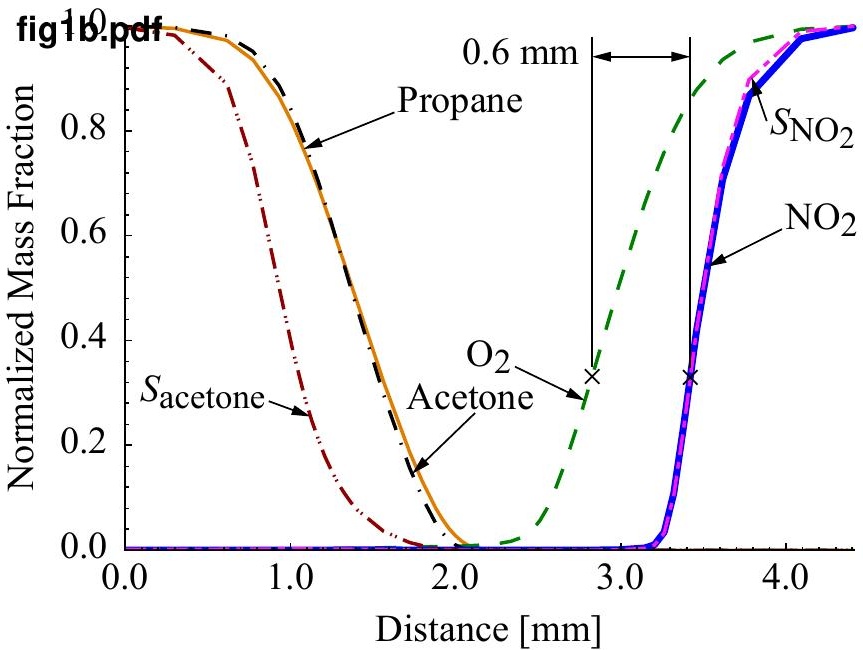




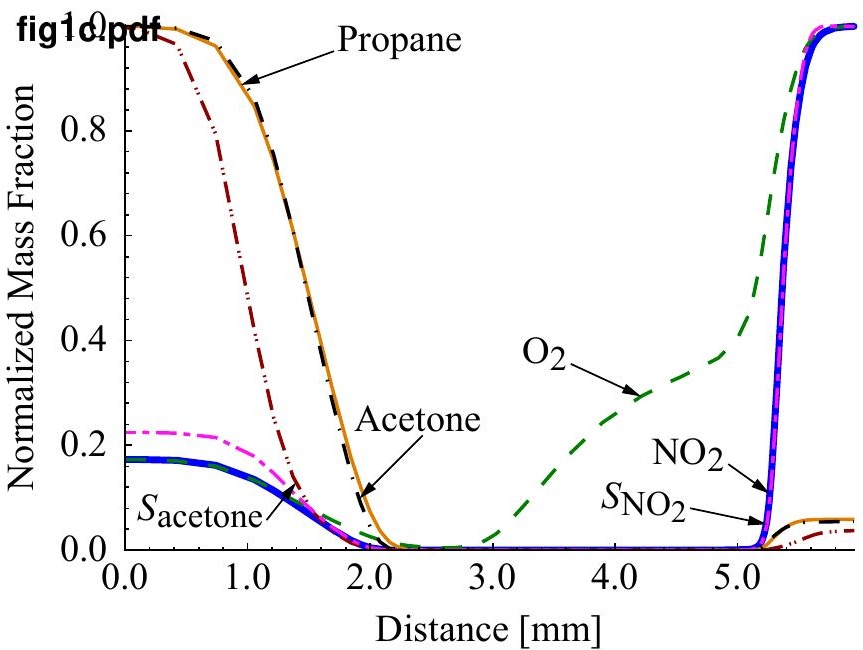




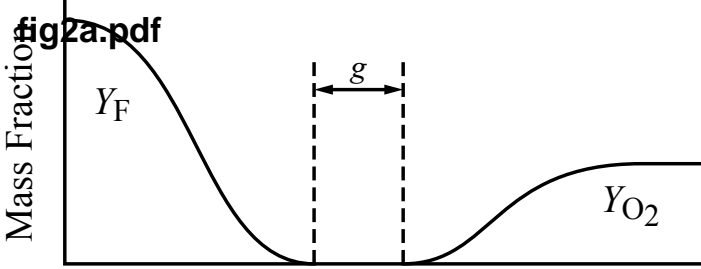

\section{Distance}




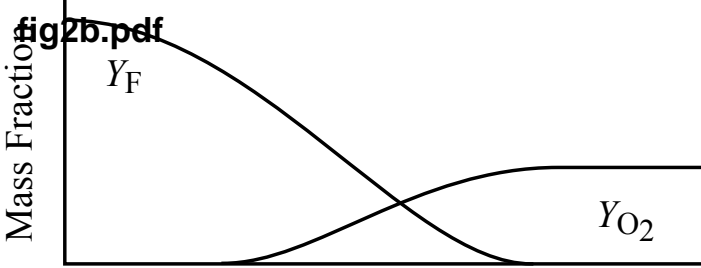

\section{Distance}




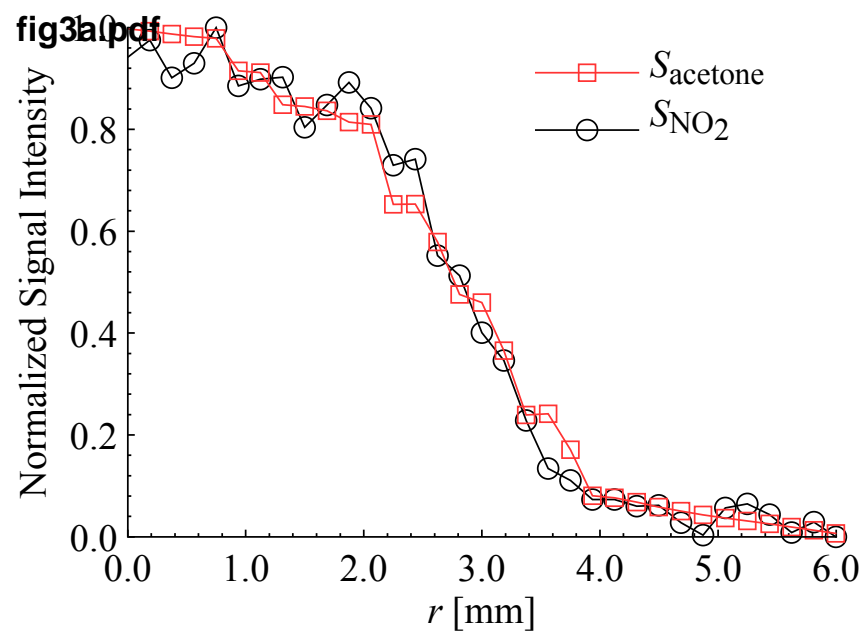




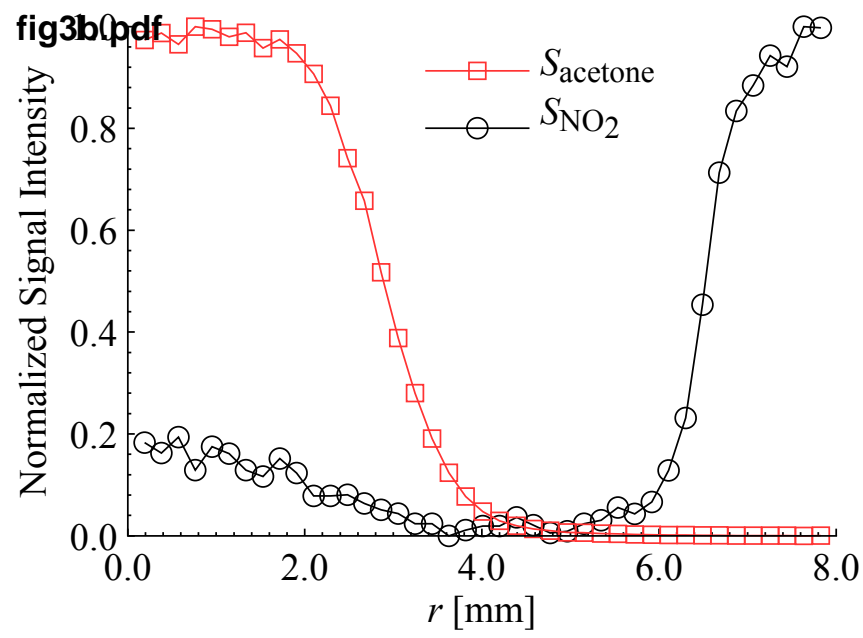


fig4.pdf
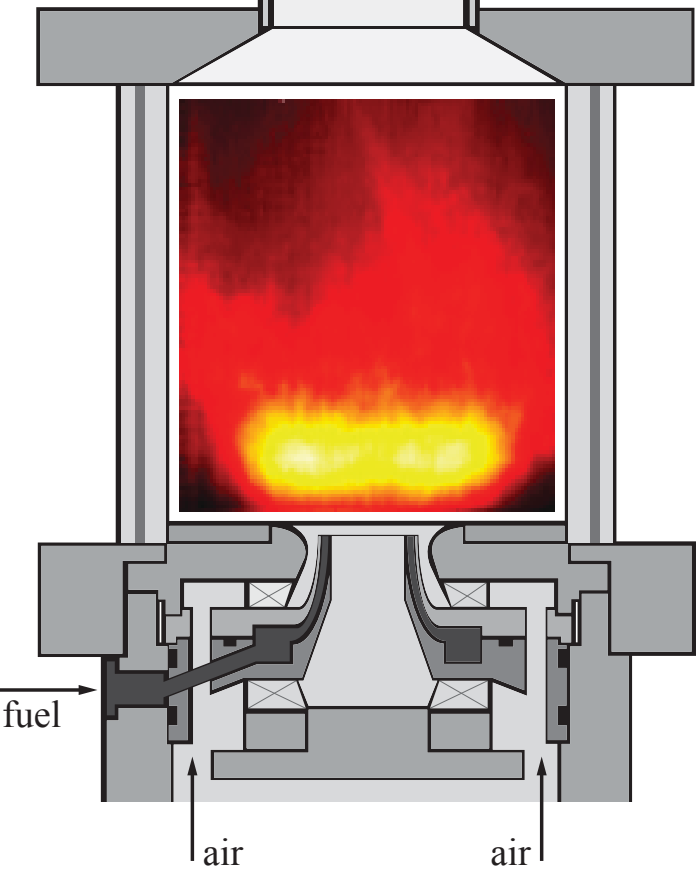


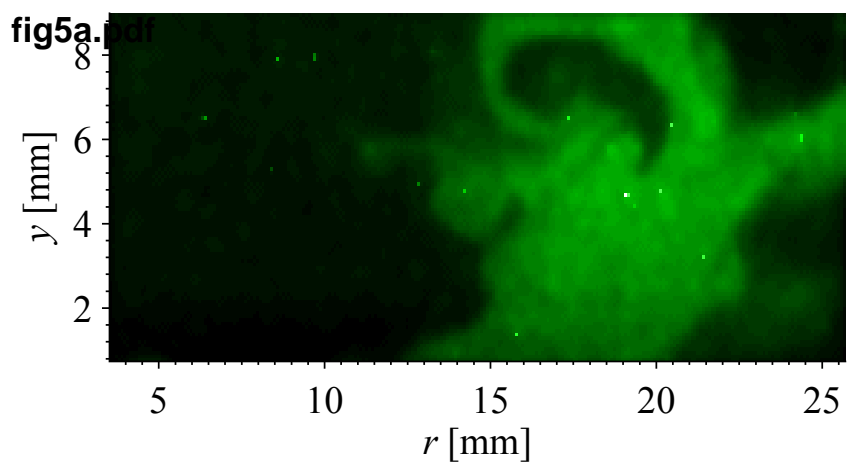


fig6b.pdf

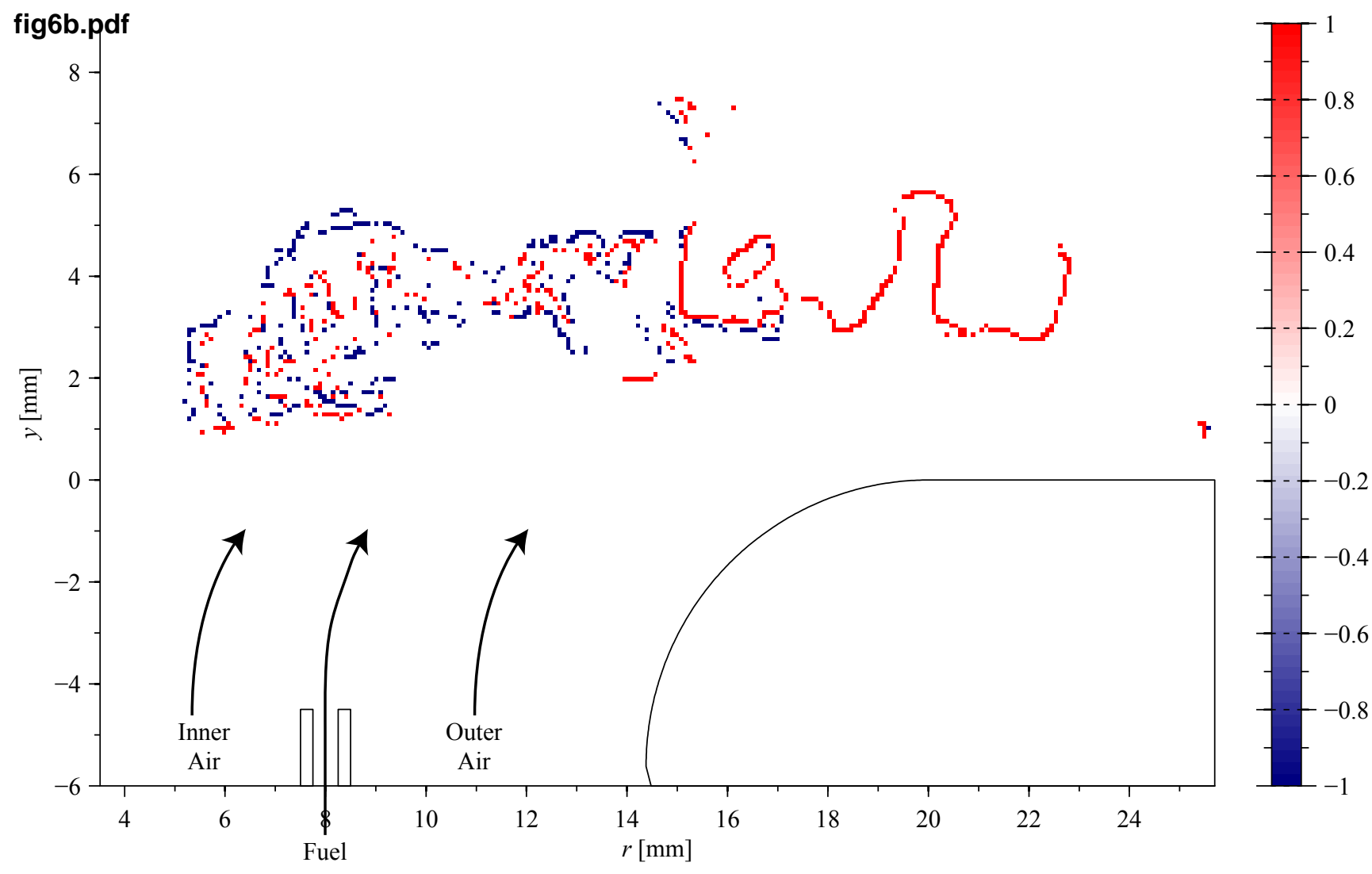




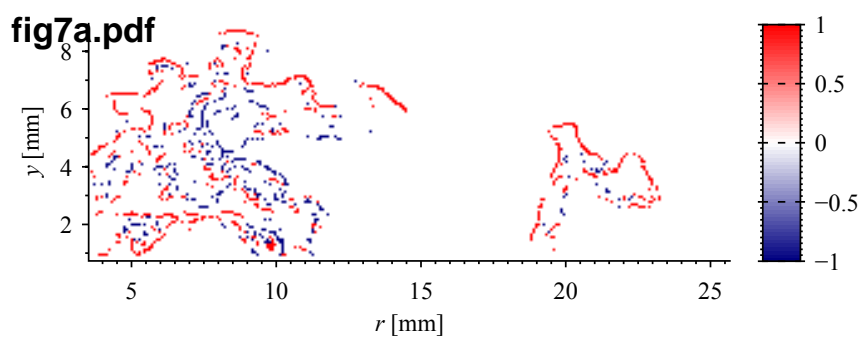




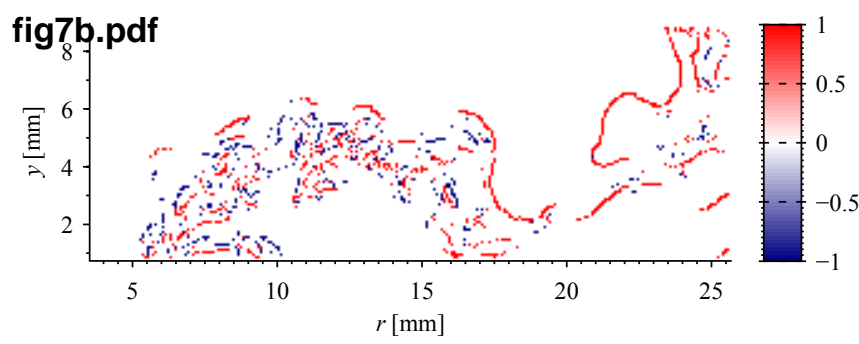




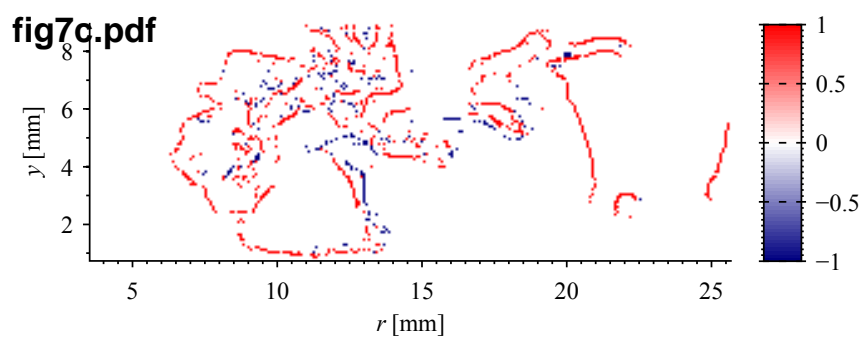




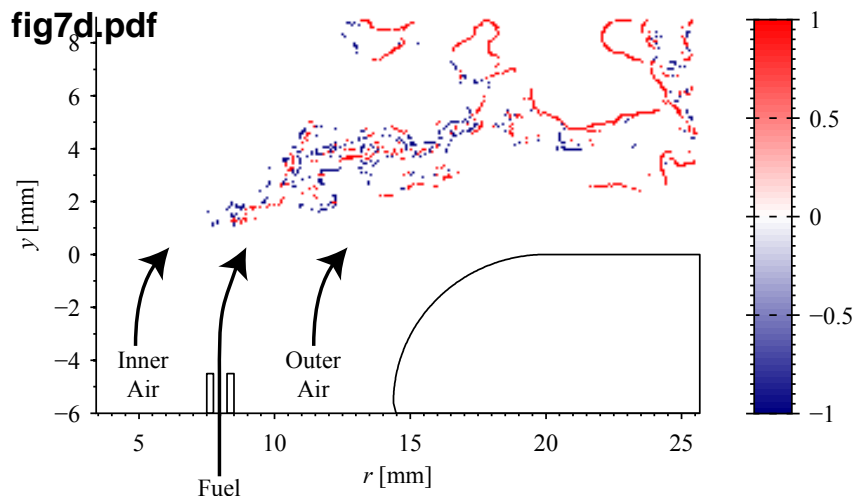




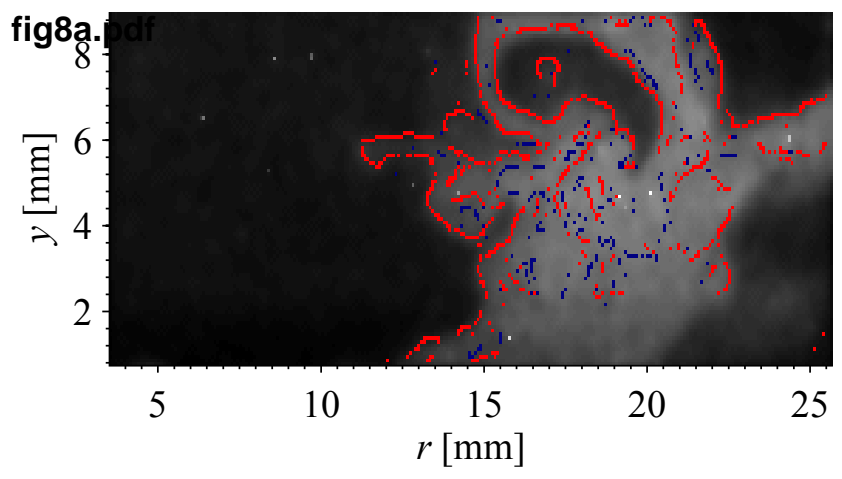




\section{fig9b.p}

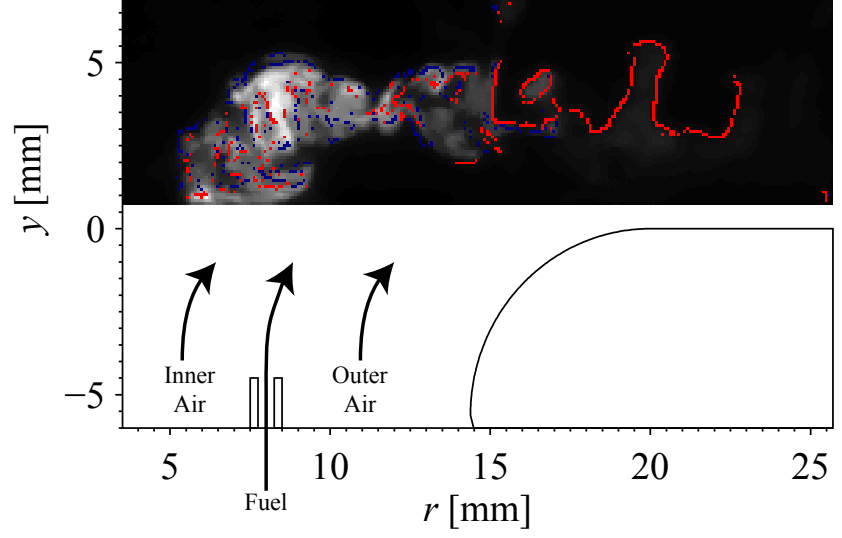


